\title{
Descentralización fiscal, calidad de gestión de gobierno y disparidades regionales en Uruguay*
}

Fiscal decentralization, governance quality, and regional disparities in Uruguay

\author{
LeONEL Muinelo-Gallo** \\ AdRIÁn RoDRÍGUEZ MiRANDA**
}

\begin{abstract}
Resumen
En este artículo analizamos el rol mediador de la calidad de gestión de gobierno en la relación entre descentralización fiscal y disparidades regionales. Trabajos previos han argumentado que la descentralización fiscal cuenta con el potencial para reducir los diferenciales de ingresos entre regiones, aunque este efecto puede verse obstaculizado por la existencia de problemas de gobernabilidad asociados a las autoridades a nivel subnacional. Nuestra evidencia empírica basada en una muestra de departamentos (regiones) de Uruguay, durante el período 1990-2010, brinda cierto respaldo a esta idea. Los resultados obtenidos señalan que la descentralización fiscal promociona la convergencia regional, y que este efecto se ve potenciado en marcos que exhiben una mayor calidad de gestión de gobierno.
\end{abstract}

Palabras clave: Descentralización fiscal, disparidades regionales, calidad de gestión de gobierno, datos de panel, Uruguay.

Clasificación JEL: D73, H71, H73.

\begin{abstract}
In this paper we analyze the mediating role of governance quality in the relationship between fiscal decentralization and regional disparities. Previous work has argued that fiscal decentralization has the potential to reduce income differences across regions but that this potential may not be realized because of governance problems associated with sub-national authorities. Our empirical evidence based on a sample of departments (regions) of Uruguay over the period 1990-2010 lends support to this idea. The empirical results show that

* Los autores agradecen los valiosos comentarios de los árbitros anónimos y del Editor de Estudios de Economía, los que ayudaron a mejorar la calidad de nuestro trabajo.

** Instituto de Economía, Universidad de la República, Montevideo, Uruguay. Autor de contacto: Tel.: +598 24000466; fax: +598 24089586. Dirección: Joaquín Requena 1375, Montevideo, Uruguay, C.P.: 11200. E-mail: lmuinelo@iecon.ccee.edu.uy (Leonel MuineloGallo); adrianrm@iecon.ccee.edu.uy (Adrián Rodríguez Miranda).
\end{abstract}


fiscal decentralization promotes regional convergence, and this effect is boosted in high governance quality settings.

Key words: Fiscal decentralization, regional disparities, governance quality, panel data, Uruguay.

JEL Classification: $D 73, H 71, H 73$.

\section{INTRODUCCIÓN}

Si la descentralización fiscal incrementa o reduce las disparidades regionales es una cuestión que ha preocupado a los economistas a través del tiempo. Una de las cuestiones fundamentales de por qué la descentralización fiscal puede no contribuir a la convergencia regional, y que exploramos en este artículo, es la calidad de gestión de gobierno. En un contexto de relación entre descentralización y disparidades regionales se ha argumentado que la descentralización fiscal puede agravar los problemas administrativos y/o de corrupción, lo cual podría atenuar o eliminar los efectos inducidos hacia la convergencia desde la descentralización fiscal.

La importancia de la calidad de gobierno para explicar la relación entre descentralización y convergencia regional ha sido sugerida por varios trabajos empíricos basados tanto en estudios de países específicos como en paneles de países. Hasta la fecha, esta evidencia destaca una relación distinta entre descentralización fiscal y disparidades regionales según el grado de desarrollo de los países. Mientras la descentralización tiende a incrementar las disparidades regionales en países en vías de desarrollo, las reduce en los países de altos ingresos. Debido a que estos últimos disfrutan de mejores indicadores de gobernabilidad, y considerando los problemas de gobernanza que podrían estar asociados con la descentralización fiscal, esto ha llevado a los economistas a proponer, aunque no demostrar empíricamente, la idea de que este impacto diferencial de la descentralización se debe a diferencias en la calidad de gobierno.

El análisis de estas cuestiones resulta particularmente relevante para el caso de Uruguay por dos razones fundamentales. En primer lugar, aun siendo un país de tamaño pequeño se registran importantes divergencias entre departamentos (regiones) del país ${ }^{1}$. La Figura 1 ilustra esta situación considerando la relación entre el ingreso per cápita de los hogares de cada departamento respecto a la media del departamento de Montevideo para tres momentos del período 1990-2010.

De hecho, estas diferencias entre departamentos, aunque con ciertas variaciones en el período, han mantenido cierta regularidad temporal que evidencia un rezago relativo importante de los departamentos del norte y noreste del país, al tiempo que los departamentos del sur, sobre todo en el eje costero sur que va desde Colonia hasta Maldonado, son los que muestran un mayor ingreso relativo.

1 Uruguay se divide en 19 departamentos que son el segundo nivel de gobierno luego del Gobierno Central. Para un detalle de la división política de Uruguay, ver Apéndice 1. 


\section{FIGURA 1}

RELACIÓN ENTRE INGRESO PER CÁPITA DE LOS HOGARES DE CADA DEPARTAMENTO Y EL VALOR MEDIO DE MONTEVIDEO
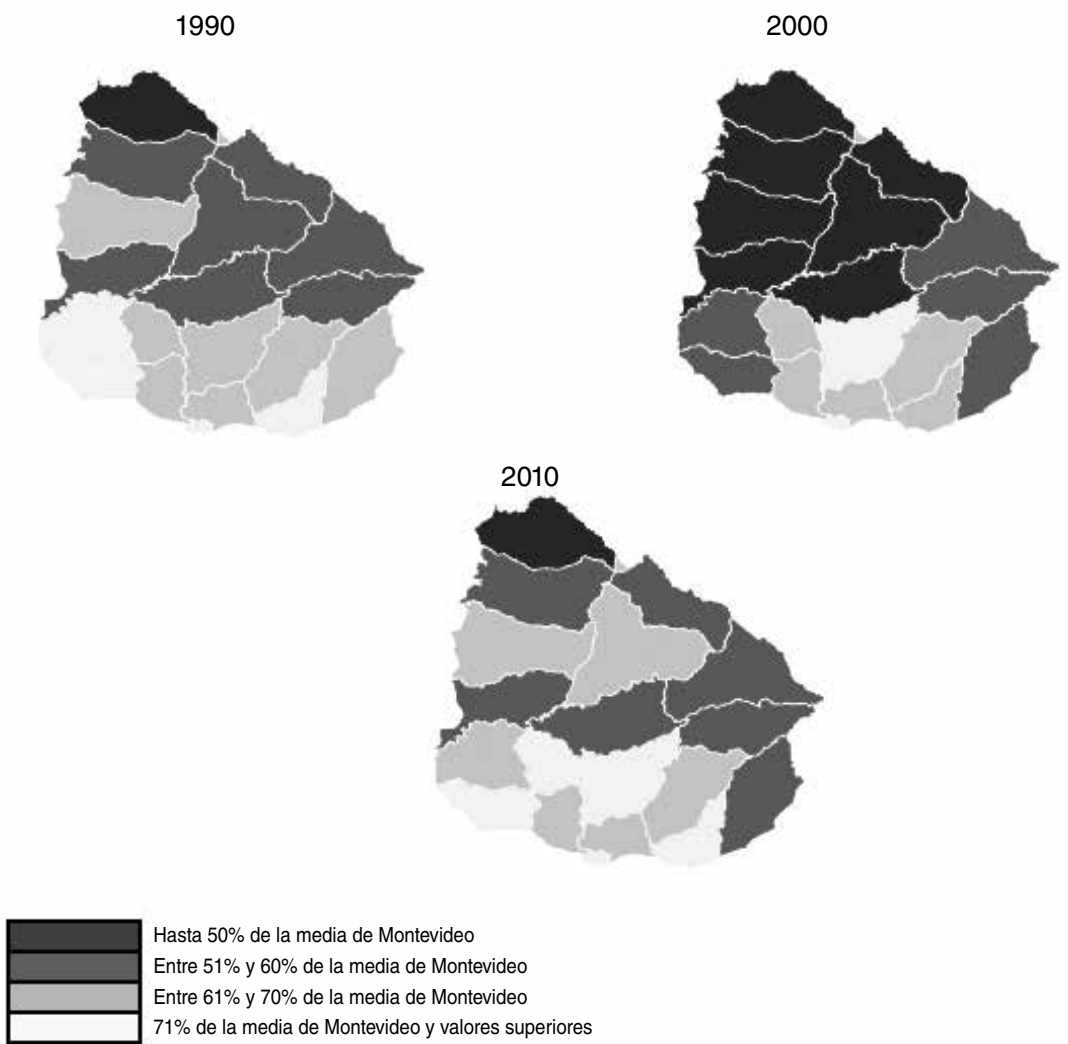

Hasta $50 \%$ de la media de Montevideo Entre $51 \%$ y $60 \%$ de la media de Montevideo Entre $61 \%$ y $70 \%$ de la media de Montevideo $71 \%$ de la media de Montevideo y valores superiores

Fuente: Elaboración propia a partir de Instituto Nacional de Estadística de Uruguay.

En segundo lugar, otro aspecto importante a considerar es el enorme peso de Montevideo (la capital) en la economía del país. Durante el período analizado en este artículo, el ingreso per cápita de los hogares de Montevideo se sitúa entre $120 \%$ y $130 \%$ del ingreso per cápita medio nacional ${ }^{2}$. Si se considera el Producto Interno Bruto (PIB) en el período analizado, Montevideo representa cerca del $60 \%$ del PIB nacional.

A su vez, ante este macrocefalismo capitalino, la situación entre los departamentos del interior del país no es homogénea, lo que se puede apreciar en la Figura 1. Existen departamentos que muestran una mayor cercanía a los valores de ingresos de Montevideo, mientras que otros muestran condiciones de rezago que se mantienen en el tiempo.

2 Encuesta Continua de Hogares, Instituto Nacional de Estadística de Uruguay. 
Considerando este contexto, el presente trabajo busca explorar en qué medida una mayor descentralización fiscal, que implique una menor dependencia de la administración central en la composición de los ingresos del gobierno local departamental, puede contribuir a una mejora relativa de ingresos en los departamentos más rezagados y, en general, a una reducción de las disparidades regionales. Además, interesa analizar bajo qué condiciones sería esperable dicho resultado y qué factores pueden estar incidiendo en ello. En particular, considerando el marco de análisis propuesto, en este artículo empírico exploramos el rol mediador de la calidad de gestión de gobierno en la relación entre descentralización fiscal y disparidades regionales en Uruguay. Basados en un análisis a nivel regional para un país de ingreso medio, como es Uruguay, contrastamos la hipótesis de que los problemas atribuidos a la descentralización se ven agravados en departamentos con problemas de gobernanza, entendida como calidad de gestión de gobierno, o, contrariamente, que estos problemas se vean mitigados en contextos con alta calidad de gestión de gobierno.

Nuestros resultados empíricos, basados en un panel balanceado de 18 departamentos de Uruguay, para el período 1990-2010, brindan respaldo a esta hipótesis. En particular, los tests empíricos realizados sugieren que la descentralización fiscal promociona la convergencia regional, y que esta convergencia se ve potenciada en marcos que exhiben una mayor calidad de gestión de gobierno.

El artículo está estructurado de la siguiente forma. En la sección 2 se realiza una revisión de las contribuciones teóricas y empíricas que han explorado cómo la descentralización fiscal podría afectar las disparidades regionales. La sección 3 realiza un breve análisis del proceso descentralizador en Uruguay. En la sección 4 describimos cómo hemos medido las variables clave utilizadas en el análisis empírico. La sección 5 detalla nuestra metodología empírica. Luego, en la sección 6 presentamos los hallazgos empíricos y algunos análisis de robustez. Finalmente, la sección 7 presenta nuestras conclusiones y discute ciertas implicaciones de política.

\section{DESCENTRALIZACIÓN FISCAL Y DISPARIDADES REGIONALES: UN BREVE REPASO DE LA LITERATURA}

Si la descentralización fiscal aumenta o reduce las disparidades regionales es una cuestión que ha preocupado a los investigadores de estos temas durante varios años. Desde el punto de vista teórico, existen varias razones por las que la descentralización de los recursos y las erogaciones fiscales pueden contribuir a la convergencia regional. En primer lugar, un mayor grado de autonomía fiscal puede reducir las disparidades regionales, ya que una mejor calidad de información por parte de los gobiernos locales posibilita la implementación de políticas más específicas. De hecho, los gobiernos a nivel subnacional cuentan con más y mayor calidad de información sobre las necesidades de sus votantes y, en consecuencia, les resulta más fácil ajustar sus políticas a las preferencias locales (Oates, 1972). Esto debería conducir a políticas más eficaces para fomentar el desarrollo económico regional y, en última instancia, podría ayudar a reducir las disparidades regionales (Oates, 1993). En segundo lugar, la descentralización puede también atenuar las disparidades regionales al propiciar 
un entorno fiscal más competitivo. En la medida en que la descentralización fiscal puede promocionar la competencia interjurisdiccional por los recursos fiscales, se podría generar un sistema de penalización de los gobiernos locales ineficaces y, en consecuencia, promover la convergencia regional (Brennan y Buchanan, 1980; Weingast, 1995; McKinnon, 1997; Qian y Weingast, 1997). En relación a esto último, los votantes pueden utilizar como punto de referencia los resultados obtenidos por los gobiernos de cada jurisdicción, propiciando una mayor eficiencia en la provisión de bienes públicos locales (Salmon, 1987; Breton, 1996).

Sin embargo, existen varias vías a través de las cuales la descentralización fiscal puede ampliar las disparidades regionales. Dado que la descentralización significa tomar recursos de la administración central, se debilita el alcance de la redistribución interregional que puede ser dirigida hacia la convergencia por parte de este gobierno central (Prud'homme, 1995). Relacionado con ello, la descentralización puede aumentar la capacidad de frenar las salidas netas de recursos por parte de los gobiernos subnacionales de las regiones más ricas (Rodríguez-Pose y Ezcurra, 2010). A su vez, en contextos descentralizados, donde las posibilidades de redistribución por parte del gobierno central son más limitadas, las regiones más ricas y con una mayor base impositiva pueden financiar bienes públicos locales a tasas impositivas más bajas (o financiar más bienes públicos con tasas similares), algo que puede llevarlos a atraer los recursos de las regiones pobres, lo cual también aumenta las disparidades regionales (Prud'homme, 1995; Keen y Marchand, 1997; Oates, 1999).

Otra dimensión a través de la cual un mayor grado de descentralización fiscal puede no contribuir a la convergencia regional, y que vamos a explorar en este artículo, refiere a los problemas relacionados con la calidad de gobierno. La calidad institucional ha sido identificada como un factor importante para explicar el desarrollo económico a nivel de país (Acemoglu et al., 2005; Rodrik et al., 2004), y existe un creciente reconocimiento de que también juega un papel importante en la explicación del desarrollo regional (Rodríguez-Pose, 2010; Tabellini, 2010). En un contexto de relación entre descentralización y disparidades regionales, se ha argumentado que la descentralización fiscal puede agravar los problemas de corrupción e incapacidad administrativa, lo que, a su vez, puede reducir o eliminar los efectos inductores hacia la convergencia regional de ingresos por parte de la descentralización fiscal. Otro argumento importante es que la descentralización puede empeorar los problemas de gobernabilidad de las administraciones subnacionales reduciendo o eliminando sus beneficios esperados (Martínez-Vázquez y MacNab, 2003). Más específicamente, los problemas de corrupción y de calidad administrativa pueden distorsionar la asignación de recursos en los niveles inferiores de gobierno, debido a la existencia de una mayor discrecionalidad por parte de los gobiernos locales. De hecho, el gobierno central puede ser más fácilmente monitoreado y estar menos expuesto a problemas de free-rider por parte de grupos de interés a nivel subnacional (Prud'homme, 1995; Bardhan y Mookherjee, 2000; Bardhan, 2002). Finalmente, los gobiernos de las regiones donde los factores inmóviles son más numerosos que los móviles, o regiones que no son competitivas por alguna razón estructural, pueden renunciar a las políticas de negociación "amistosas", dedicándose de esta forma a políticas de tipo predatorio (Rodden y Rose-Ackerman, 1997; Cai y Treisman, 2005). 
La importancia del rol mediador de la calidad del gobierno en la relación entre descentralización fiscal y convergencia regional también ha sido analizada empíricamente. Esta evidencia reporta una relación distinta entre descentralización fiscal y disparidades regionales según el nivel de desarrollo de los países. Más específicamente, la descentralización tiende a acentuar las desigualdades regionales en los países en vías de desarrollo, y las reduce en los países de ingresos altos (Rodríguez-Pose y Ezcurra, 2010; Lessmann, 2012). En estudios de casos, la descentralización fiscal ha aumentado las disparidades regionales en China (Kanbur y Zhang, 2005; Qiao et al., 2008), Filipinas (Silva, 2005) y Colombia (Bonet, 2006), al tiempo que ha reducido las disparidades en los EE.UU. (Akai y Hosio, 2009) e Italia (Calamai, 2009). En virtud de que, en general, los países de altos ingresos disfrutan de una mejor "gobernabilidad", y teniendo en cuenta los problemas anteriormente mencionados que puedan estar asociados a los procesos de descentralización fiscal, esto ha llevado a los estudiosos de estos temas a proponer, aunque no testear empíricamente, la idea de que este impacto diferencial de la descentralización se debe a la diferencia en la calidad del gobierno en cada escenario.

\section{DESCENTRALIZACión FiSCAL EN UN PAís DE INGRESO MEdio: El CaSO DE URUGuaY}

De acuerdo con lo expuesto anteriormente, la descentralización fiscal podría promover la convergencia regional en contextos de alta calidad de gobierno, aunque también podría conducir a mayores disparidades regionales en contextos con problemas de gobernabilidad. Este es un argumento muy relevante para ser contrastado y discutido para el caso de Uruguay. De hecho, desde la reforma Constitucional de $1996^{3}$ y la reciente Ley de Descentralización Política y Participación Ciudadana de 2010, se viene impulsando en Uruguay un proceso que busca avanzar hacia una mayor descentralización. Como señala Arocena (2008; pp.17), la “...descentralización supone revertir el proceso hegemónicocentralista e incentivar la conformación de sociedades locales de base territorial, densas socialmente y dinámicas en su capacidad de generar riqueza. Se trata de restablecer un equilibrio central-local que el centralismo no ha permitido desarrollar...". Por lo tanto, la descentralización implica necesariamente la transferencia desde el nivel de gobierno central hacia los gobiernos locales de cierta hegemonía en la toma de decisiones. Para que esto se cumpla, el proceso debe comprender tres dimensiones referidas a la transferencia de responsabilidades, competencias y recursos desde los niveles centrales a los subnacionales.

3 La reforma constitucional de 1996, en su artículo 230, establece dos órganos de gobierno en los que participan los Gobiernos Departamentales (GD) y que adquieren de esta forma rango constitucional con competencia en el tema de la descentralización. Estos órganos son: el Congreso de Intendentes (Jefes de los GD) y la Comisión Sectorial de Descentralización (integrada por 6 delegados de los ministerios nacionales y 6 delegados del Congreso de Intendentes, y que es coordinada por la Oficina de Planeamiento y Presupuesto de Presidencia de la República). 
Sin embargo, aunque la Constitución de 1996 posee una orientación descentralizadora en términos de posibilidades o potenciales cambios, estos cambios muchas veces no se han materializado. Por ejemplo, el estudio de CEDES (2010; pp. 49) argumenta que "...vvarias incorporaciones y/o modificaciones de la Constitución de 1996 pueden considerarse medidas descentralizadoras. No obstante, su carácter general y, en algunos casos, indeterminado, es un indicador de los problemas pendientes para construir un fuerte acuerdo que promueva una mayor autonomía y capacidades de los gobiernos de segundo nivel...". El mismo estudio señala entre las medidas que permiten una mayor oportunidad para la descentralización, la posibilidad que los Gobiernos Departamentales (GD) tengan libertad en cómo usar los recursos provenientes de la alícuota del gobierno nacional que les corresponde por transferencias (artículo 297 de la Constitución de 1996), modificando la situación anterior que establecía que debían ser utilizados necesariamente para obras de infraestructura.

Por otra parte, la Constitución permite legislar para extender el ámbito de la aplicación de los tributos departamentales y ampliar las fuentes sobre las cuales estos pueden recaer (artículo 298), lo que incrementaría la porción de ingresos propios de los gobiernos departamentales.

Estos cambios en la legislación ocurren en un país centralista donde las competencias formales de los GD (segundo nivel de gobierno) se reducen a la prestación de servicios como el pavimento y mantenimiento de caminos, la organización del tránsito (incluyendo lo referente a la patente de vehículos y licencias de conducir), el transporte colectivo, la limpieza, la iluminación pública, el servicio de necrópolis, los controles sanitarios y las cuestiones relacionadas con el ordenamiento territorial (aspecto que se refuerza con la reciente Ley de Ordenamiento Territorial y Desarrollo Sostenible). A pesar de ello, en la práctica los GD han ido asumiendo otras atribuciones que no responden a esas competencias tradicionales. Esto se verifica desde 1985 por medio de un proceso por el que los GD fueron ampliando sus competencias de facto hacia temas relacionados con la promoción del desarrollo social y económico, adoptando en los últimos tiempos la definición del desarrollo local como una de sus metas y materias de actuación (ver Rodríguez Miranda, 2014).

Considerando este contexto, la Figura 2 muestra que los ingresos presupuestales totales de los GD se han incrementado de forma importante durante el período 1990-2010.

Las nuevas responsabilidades (vinculadas a aspectos del desarrollo económico y social) que han asumido los gobiernos departamentales implican grandes desafíos en términos de capacidades de gobierno para gestionar y ejecutar en forma adecuada los presupuestos. A pesar de ello, el esquema de transferencias desde el Gobierno Central a los GD no está diseñado para la reducción de asimetrías regionales ${ }^{4}$. Este esquema define la alícuota de cada departamento en

4 Las transferencias de recursos desde el Gobierno Central al ámbito departamental se establecen en dos artículos de la Constitución nacional: los artículos 214 (Transferencias) y 298 (Fondo de Desarrollo del Interior, FDI). Sin embargo, las alícuotas que corresponden a cada departamento y su implementación no se establecen en la Constitución. Debiendo establecerse nuevamente con cada nuevo gobierno nacional por medio de la Ley de Presupuesto Nacional (ver, Rodríguez Miranda, 2014). 
FIGURA 2

EVOLUCIÓN DEL PIB NACIONAL E INGRESOS

PRESUPUESTALES DEPARTAMENTALES

Valores constantes promedio de los 18 departamentos de Uruguay (1990-2010)

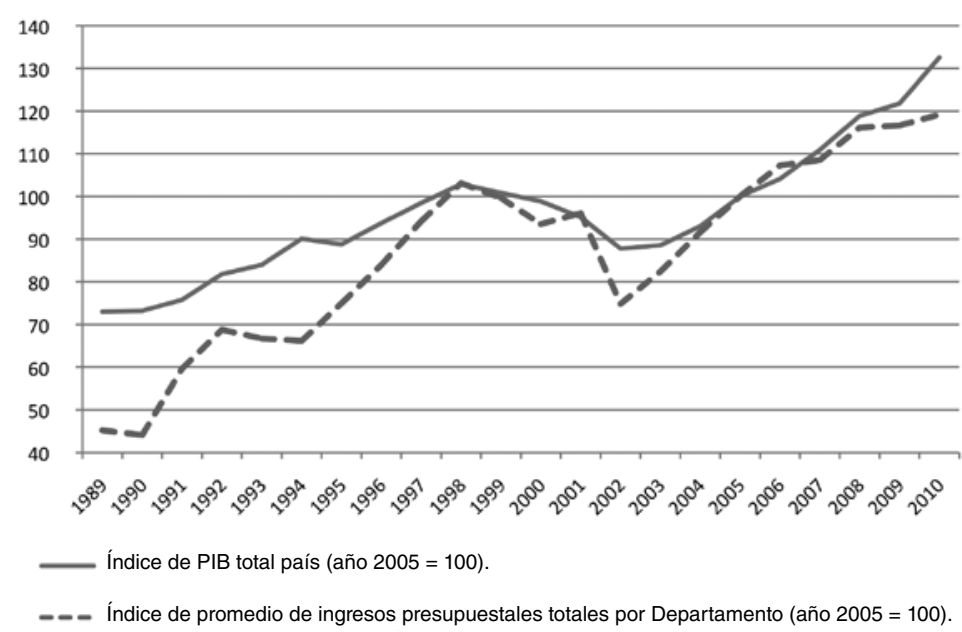

Fuentes: Elaboración propia a partir de Banco Central del Uruguay, y Oficina de Planeamiento y Presupuesto de la Presidencia de la República.

cada quinquenio en la Ley de Presupuesto Nacional, resultando en porcentajes que reflejan las capacidades de negociación política y las trayectorias históricas respecto de cuánto recibía cada departamento, sin reflejar criterios de cohesión territorial.

En este contexto, consideramos que las capacidades de gestión y de generación (y recaudación) de ingresos propios de los gobiernos departamentales son una buena medida de mayor autonomía y capacidad de hacer frente a las nuevas responsabilidades que se vienen asumiendo en relación con la promoción del desarrollo y a la prestación de mejores servicios públicos locales.

Respecto del rol que la descentralización, considerada como una mayor capacidad y autonomía fiscal, podría tener para reducir las disparidades regionales en Uruguay, la Figura 3 muestra una correlación positiva entre el nivel de ingreso per cápita de los departamentos y el porcentaje de recursos propios en los ingresos totales del Gobierno General Nacional (impuestos, tasas y rentas que son potestad de fijación y recaudación por parte del GD).

A su vez, la Figura 4 muestra una correlación negativa entre nuestra medida de descentralización fiscal (porcentaje de recursos propios en el total de ingresos del gobierno general) y el coeficiente de variación de ingresos per cápita de los hogares utilizado como indicador de disparidad regional (ver sección 4). 


\section{FIGURA 3}

DESCENTRALIZACIÓN FISCAL E INGRESO PER CÁPITA DE LOS HOGARES A NIVEL DEPARTAMENTAL

Valores promedio (1990-2010)

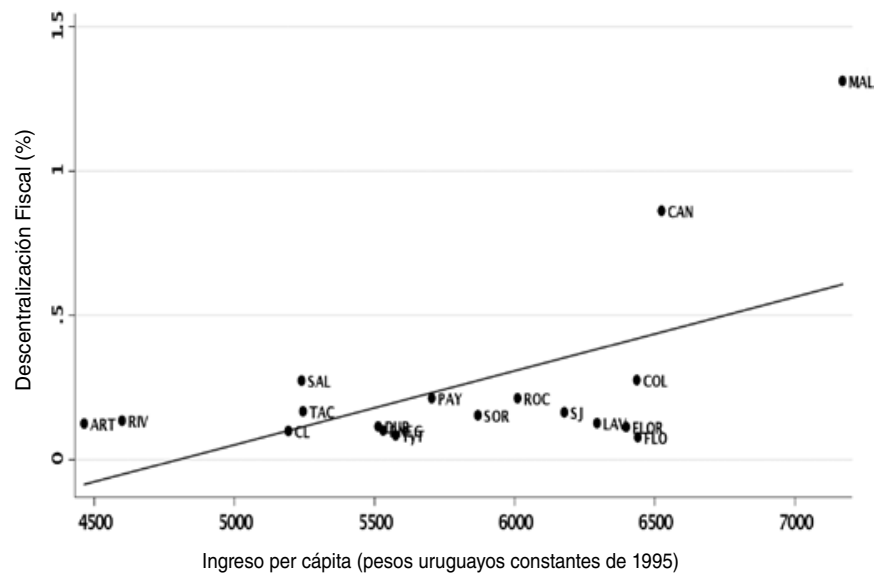

Notas: i) Descentralización fiscal se mide como el porcentaje que representan los ingresos de origen departamental en el total de ingresos del Gobierno General Nacional; ii) Ingreso per cápita (a pesos constantes de 1995) corresponden al ingreso per cápita de los hogares de la Encuesta Continua de Hogares del Instituto Nacional de Estadística de Uruguay.

Fuentes: Instituto Nacional de Estadística de Uruguay, y Oficina de Planeamiento y Presupuesto de la Presidencia de la República de Uruguay.

\section{FIGURA 4}

\section{DESCENTRALIZACIÓN FISCAL Y DISPARIDADES REGIONALES EN URUGUAY}

Valores promedio (1990-2010)

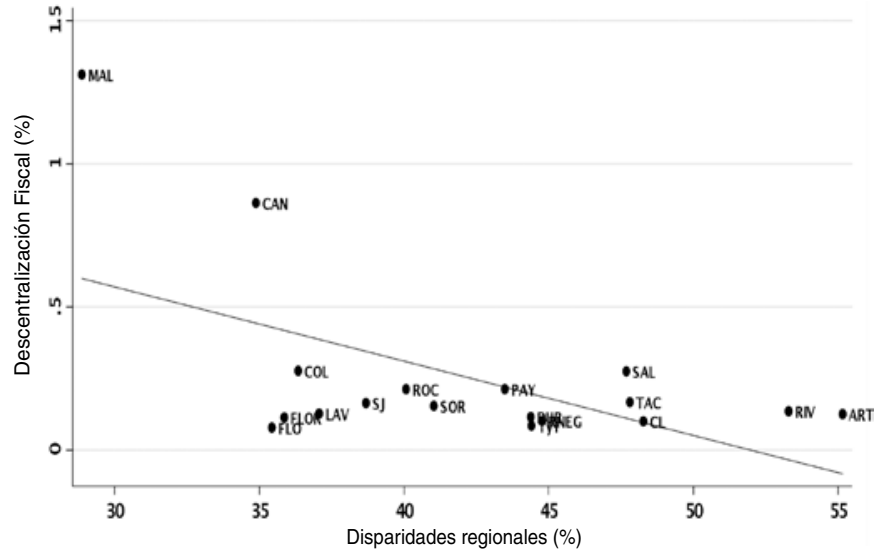

Notas: i) Descentralización fiscal se mide como el porcentaje que representan los ingresos de origen departamental en el total de ingresos del Gobierno General Nacional; ii) Disparidades regionales corresponden al coeficiente de variación calculado con el ingreso promedio per cápita de los hogares.

Fuentes: Instituto Nacional de Estadística de Uruguay, y Oficina de Planeamiento y Presupuesto de la Presidencia de la República de Uruguay. 


\section{MEdiCión DE LAS PRINCIPALES VARIABLES}

En esta sección analizamos los indicadores empleados para medir las disparidades regionales, descentralización fiscal y calidad de gestión de gobierno en Uruguay. Construimos un panel balanceado de 18 departamentos durante el periodo 1990-2010, basando nuestra selección de departamentos y período en la disponibilidad, frecuencia y calidad de los datos correspondientes a estos indicadores 5 .

Para medir las disparidades regionales utilizamos una aproximación al coeficiente de variación (CV), utilizado frecuentemente en la literatura focalizada en disparidades regionales ${ }^{6}$. Más específicamente, nuestro indicador de disparidades toma la siguiente forma:

$$
C V=\left(\left(\frac{1}{\bar{y}_{M T V, t}}\left(\bar{y}_{M T V, t}-y_{i, t}\right)^{2}\right)^{1 / 2}\right) * 100
$$

donde $\bar{y}_{M T V, t}$ es el ingreso per cápita medio del departamento de Montevideo en el momento t, mientras que $y_{i t}$ es el ingreso per cápita del departamento $i$ en el momento $t$. Este indicador refleja las disparidades de los diferentes departamentos en cada año en relación con el departamento de Montevideo. Varía entre 0\% (máxima igualdad) y 100\% (máxima disparidad). La selección de Montevideo como valor de referencia responde al análisis previo que se ha realizado sobre las características del desarrollo regional en el país y al posicionamiento de la capital como la región más rica del país.

En la literatura empírica cross-country, una fuente que ha sido ampliamente utilizada para medir la calidad de gobierno es la base de datos International Country Risk Guide (ICRG) elaborada por el Grupo de Servicios de Riesgo Político para evaluar los riesgos políticos, económicos y financieros entre los países ${ }^{7}$. De hecho, tal como señalan Kyriacou y Roca-Sagalés (2009, página 10): "...La elaboración de los diferentes indicadores que comprende esta base de datos se basa en las percepciones de una red mundial de expertos en una serie de variables específicas de cada país, como la corrupción, el estado de derecho y la calidad de la burocracia a través de instituciones y jurisdicciones estatales (ya sea a nivel local, regional o central). La corrupción se refiere a la demanda de sobornos por parte de los órganos políticos y administrativos, así como el clientelismo, el nepotismo, etc. Por su parte, la variable referida a estado de derecho (nombrada como ley y orden) evalúa la fuerza y la imparcialidad del sistema judicial, así como la percepción popular sobre la ley. Finalmente, la

5 Ver el Apéndice 2 para la lista de departamentos incluidos, el Apéndice 4 para las fuentes de datos utilizadas y el Apéndice 5 para la estadística descriptiva. Resulta importante mencionar que el panel de datos especialmente construido para este estudio se encuentra libremente disponible por parte de los autores ante quien desee solicitarlo.

6 Ver Williamson (1965), Ezcurra y Pascual (2008), Lessmann (2009), y Rodríguez-Pose y Ezcurra (2010).

7 Ver, por ejemplo, Mauro (1995), La Porta et al. (1999), Adsera et al. (2003); Ederveen et al. (2006) y Bähr (2008). 
calidad de la burocracia se refiere a la fuerza, la experiencia, la autonomía, el reclutamiento y el mecanismo de formación de la administración pública. Debido a que las dos primeras dimensiones se miden en una escala de 0 a 6 , mientras que la última varía de 0 a 4, se normaliza cada dimensión entre 0 y 1. En este sentido, el indicador de calidad de gobierno generalmente utilizado se obtiene mediante la suma de estos valores normalizados y, por tanto, varía de 0 a 3, donde un número mayor implica una mayor calidad de gobierno..."

Debido que en el caso específico de estudios regionales de países estas dimensiones varían muy poco, básicamente no es posible obtener una variación importante ni en el tiempo, ni entre regiones y, además, este tipo de información a nivel regional muchas veces no se encuentra disponible; en este artículo aproximamos una medida de la calidad de gobierno a través de la construcción de un indicador de calidad de gestión departamental.

Más específicamente, para aproximar la calidad de gobierno referida a los aspectos de gestión del GD elaboramos un indicador que consta de tres dimensiones: resultado fiscal del gobierno departamental (que se considera en puntos porcentuales del PIB departamental), el porcentaje de funcionarios presupuestados sobre el total de funcionarios del gobierno departamental, y el salario medio pagado a los funcionarios (que se calcula como las remuneraciones del personal dividido el número de funcionarios, en precios constantes de 1995). Cada una de estas dimensiones se expresa en una escala de 0 a 3 , de acuerdo a la distribución empírica de cada una de las variables en el período analizado ${ }^{9}$, de modo que el valor 0 indica el peor desempeño relativo y 3 el mejor desempeño entre los departamentos analizados para cada año (en el Apéndice 2 se da un mayor detalle sobre la construcción del indicador). El indicador final resulta de la suma simple de las tres dimensiones, por lo que varía entre 0 y 9 , donde un número mayor implica una mayor calidad de gestión de gobierno.

Con la dimensión del resultado fiscal se busca captar diferencias entre los gobiernos departamentales referidas al manejo adecuado de las necesidades de gastos en función de la disponibilidad de ingresos, lo que hace referencia a la calidad de gestión y administración de los recursos. Presentar déficit presupuestal en un año o un par de años concretos no es por sí solo un indicador de mala gestión, sin embargo, no parece saludable gastar permanentemente por encima de los ingresos. Lo que se observa en el caso uruguayo es que algunos departamentos muestran incluso más de 10 años de déficit acumulado. Ya que, como se detalla más adelante, el análisis empírico también utiliza promedios trianuales de las variables, esto permite un mejor análisis en términos de persistencia del déficit. En general, porque los datos muestran perfiles bastante diferentes entre departamentos con y sin déficit persistentes, además de la magnitud del mismo, esta variable tiene poder explicativo respecto de los modelos de gestión de los gobiernos.

8 Para ver otras aplicaciones empíricas de este indicador se recomienda Kyriacou (2012), Kyriacou y Roca-Sagalés (2009, 2011a y b, 2012, 2013)

9 De hecho, cada uno de estos umbrales, para cada una de las dimensiones que componen el índice de calidad de gestión de gobierno, se construyó de forma que no existiera ninguna escala que tuviera unas pocas observaciones, las que podrían considerarse como outliers en el ejercicio empírico. 
No es posible obtener información desagregada sobre gastos en infraestructura y servicios de los GD, y tampoco se cuenta con medidas directas de evaluación de los servicios prestados. La información muchas veces no existe, es incompleta o no es comparable entre departamentos. Por lo tanto, en este artículo se opta por utilizar algunas medidas indirectas que aproximan mejores funcionamientos y calidad de gestión, lo que implica mejores condiciones para la prestación de servicios públicos locales. En este sentido, se toma el porcentaje de funcionarios presupuestados en el total de funcionarios del GD buscando reflejar la presencia de una estructura más deseable frente a la realidad que predomina en los GD del país que muestran un alto componente de contratos a término, cargos de confianza y empleos temporales ${ }^{10}$. Una estructura de este tipo, con predominancia del vínculo temporal y de confianza, no consigue consolidar funcionarios de carrera y no genera "memoria institucional" ni capacidades en la institución más allá del período de gestión de la administración de turno.

Adicionalmente, se considera un indicador de la remuneración promedio de los funcionarios de los GD entendiendo que si la misma es relativamente alta en el contexto nacional implica una situación en la que se tiene una mejor posición para captar recursos humanos con mayor capacitación y/o formación (por ejemplo, técnicos y profesionales). No parece adecuado, para el caso uruguayo, considerar la remuneración en relación con los salarios promedio de la economía local, ya que en las economías menos dinámicas esas remuneraciones promedio son bajas y el empleo en el GD puede funcionar como un refugio para ciertas personas frente a la falta de empleo privado de calidad, aunque no atractivas para captar y mantener profesionales con cierta formación. Por otra parte, en Uruguay las distancias geográficas son relativamente cortas y la movilidad es alta para los profesionales y técnicos, por lo que las economías departamentales que pagan mejores salarios e ingresos están en mejores condiciones de captar estos recursos, sin que existan mercados locales segmentados. Por ejemplo, en 2010 los departamentos del interior que presentan menores remuneraciones rondan el $45 \%$ del valor medio de remuneraciones de Maldonado, el departamento que paga mejores salarios en el interior.

Finalmente, resulta importante señalar que si bien cada dimensión aisladamente parecería insuficiente para aproximar la calidad de gestión del GD, la suma simple que surge de estas tres dimensiones genera un indicativo fuerte sobre el desempeño de los gobiernos departamentales. Es decir, que si un GD tiene un déficit fiscal elevado y en forma persistente, si además paga remuneraciones promedio bajas y su estructura de empleo es precaria en cuanto a temporalidad y baja presencia de funcionarios de carrera, no resulta inadecuado considerar que ello es un indicio importante de una gestión con problemas, al menos en términos relativos a otros departamentos que muestran la situación contraria.

La literatura de competencia fiscal interjurisdiccional enfatiza la importancia de ligar los gastos locales con los ingresos locales. De hecho, al relacionar ambas dimensiones presupuestales se promocionaría un funcionamiento apropiado de

10 En el período aquí analizado el $50 \%$ de los GD muestran un porcentaje de presupuestados de entre $50 \%$ y $75 \%, 36 \%$ de los casos exhiben un valor entre $50 \%$ y $26 \%$, y $15 \%$ de los GD cuentan con $25 \%$ o menos de funcionarios presupuestados. 


\section{FIGURA 5}

CALIDAD DE GESTIÓN DE GOBIERNO Y DESCENTRALIZACIÓN FISCAL EN URUGUAY

Valores promedio (1990-2010)

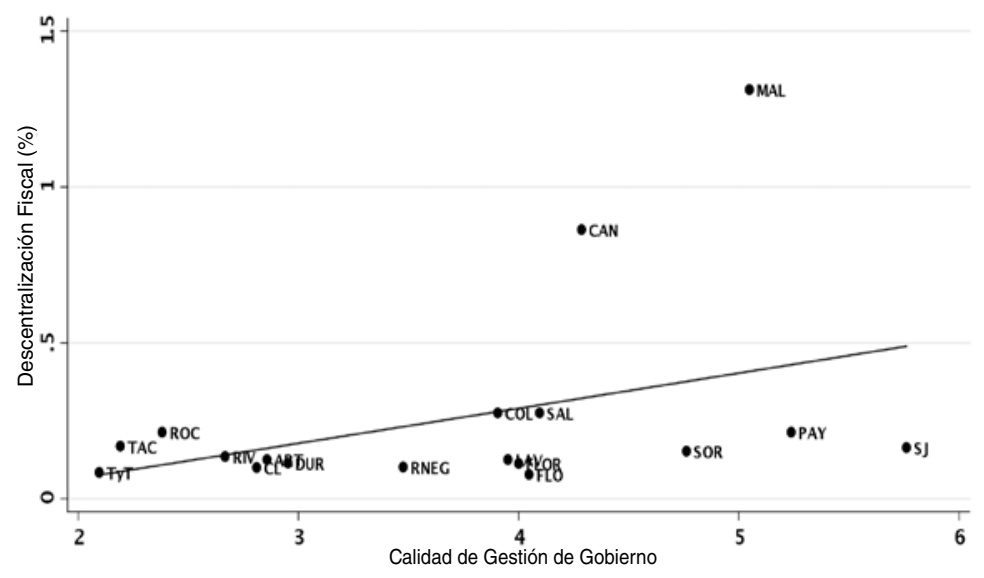

Notas: i) Descentralización fiscal se mide como el porcentaje que representan los ingresos de origen departamental en el total de ingresos del Gobierno General Nacional; ii) Calidad de gestión de gobierno es medida como la suma de tres dimensiones que varían entre 0 y 3: resultado fiscal, porcentaje de funcionarios presupuestados, remuneración media. El indicador final varía entre 0 y 9 (véase Apéndice 3).

Fuentes:Instituto Nacional de Estadística de Uruguay, y Oficina de Planeamiento y Presupuesto de la Presidencia de la República de Uruguay.

la competencia, porque las transferencias verticales pueden generar incentivos para que las autoridades locales ignoren las presiones competitivas por un mejor gerenciamiento (Jin et al., 2005; Qian y Weingast, 1997; Qian y Roland, 1998; Oates, 1999; Zhuravskaya, 2000). Considerando esto, medimos la descentralización fiscal como el porcentaje de los ingresos de gobierno departamental que tienen origen en recaudación propia sobre el total de ingresos del gobierno general. Este indicador es una medida importante del grado de autonomía fiscal que tienen los gobiernos departamentales, en la medida que dependen menos de las transferencias del Gobierno Central Nacional. Según este indicador, los departamentos más descentralizados en nuestra base de datos son Maldonado, Canelones y Colonia ${ }^{11}$, mientas que los menos descentralizados son Cerro Largo, Río Negro y Durazno ${ }^{12}$. De hecho, existe una clara correlación positiva y significativa entre los departamentos que cuentan con una mayor descentralización fiscal, así medida, y los de mayor calidad de gestión de gobierno (Figura 5).

11 El departamento de Maldonado, para el período 1990-2010, presentó una participación media de los recursos de origen departamental en los ingresos presupuestales totales del $86 \%$. Por su parte, Canelones alcanza un valor de $76 \%$ durante este período, mientras que Colonia presenta un valor promedio de $63 \%$.

12 En el período 1990-2010 los ingresos de origen departamental representaron en promedio $36 \%$ en Cerro Largo, $39 \%$ en Río Negro y $41 \%$ en Durazno. 
FIGURA 6

CALIDAD DE GESTIÓN DE GOBIERNO Y DISPARIDADES

REGIONALES EN URUGUAY

Valores promedio (1990-2010)

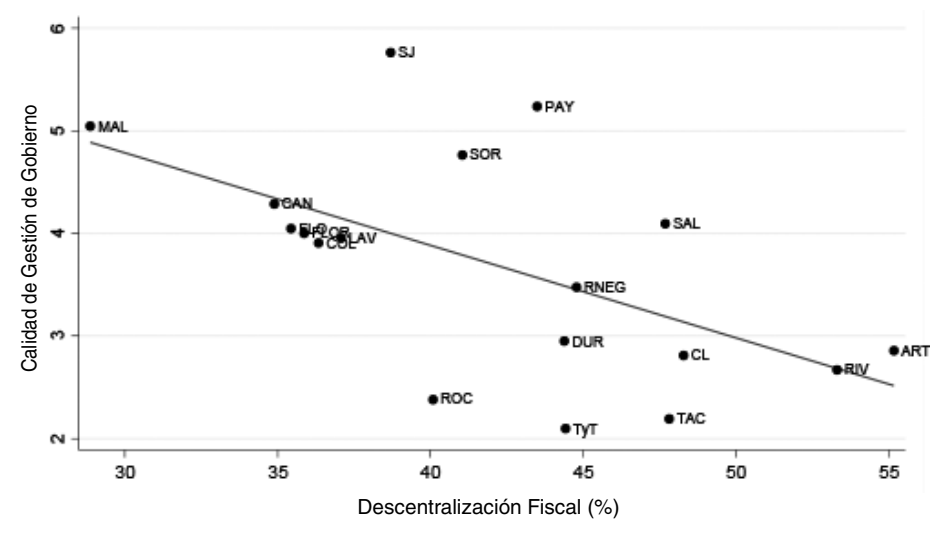

Notas: i) Calidad de gestión de gobierno es medida como la suma de tres dimensiones que varían entre 0 y 3: resultado fiscal, porcentaje de funcionarios presupuestados, remuneración media. El indicador final varía entre 0 y 9 (véase Apéndice 3); ii) Disparidades regionales corresponde al coeficiente de variación calculado con el ingreso promedio per cápita de los hogares.

Fuentes: Instituto Nacional de Estadística de Uruguay, y Oficina de Planeamiento y Presupuesto de la Presidencia de la República de Uruguay.

Adicionalmente, resulta posible observar otras dos relaciones empíricas importantes en nuestro análisis. En primer lugar, como ya hemos visto en la Figura 3 existe una relación negativa y significativa entre nuestra medida de disparidades regionales y el grado de descentralización fiscal durante el período analizado. En segundo lugar, resulta posible observar también una relación negativa y significativa entre calidad de gestión de gobierno y disparidades regionales (Figura 6).

De hecho, las relaciones establecidas en las Figuras 4 y 6 sugieren dos hipótesis importantes que intentamos testear de forma empírica. Primero, la posibilidad que un aumento en el grado de descentralización fiscal y/o en la calidad de gestión de gobierno departamental reduzca las diferencias entre regiones. Segundo, la posibilidad de que ambos efectos se complementen entre sí.

\section{Metodología empírica}

Para testear si la calidad de gestión de los gobiernos departamentales media en la relación entre descentralización fiscal y disparidades regionales estimamos el siguiente modelo base:

$$
C V_{i t}=\alpha+\beta_{1} D F_{i t}+\beta_{2} C G_{i t}+\beta_{3} D F_{i t} C G_{i t}+\beta_{4} X_{i t}+\xi_{i t}
$$


donde $i$ refiere al departamento (región), $t$ a los años, $\alpha$ es una constante, $C V_{i t}$ a las disparidades regionales, $D F_{i t}$ es nuestro indicador de descentralización fiscal, $C G_{i t}$ corresponde al indicador de calidad de gestión de gobierno; mientras que $X_{i t}$ es un vector de variables de control y $\xi_{i t}$ es el término de error. Debido a nuestra discusión previa esperaríamos que $\beta_{3}<0$, o en otras palabras, que la descentralización fiscal debería reducir la disparidades regionales en los departamentos con mayor calidad de gestión de gobierno ${ }^{13}$.

Nuestro vector de variables de control incluye el PIB real per cápita departamental, un indicador de capital humano, un índice de capacidad productiva de la tierra departamental (índice Coneat) y un indicador del peso del empleo en la industria manufacturera sobre el total del empleo en el departamento. Nuestra selección de variables de control se encuentra guiada por la necesidad de considerar aquellos factores que pudieran afectar, por un lado, la relación entre la descentralización fiscal y disparidades regionales y, por otro, la relación entre calidad de gestión de gobierno y las disparidades regionales, de forma de evitar sesgos de variables omitidas (para una definición de las variables utilizadas, ver Apéndice 4).

Empleamos un estimador de mínimos cuadrados generalizados realizables (FGLS por su denominación en inglés). De hecho, este estimador es asintóticamente más eficiente que el estimador por mínimos cuadrados ordinarios (MCO) cuando las series exhiben heterocedasticidad (Wooldridge, 2010). A su vez, utilizamos ponderadores de período tipo SUR para corregir tanto por heterocedasticidad temporal como por correlación serial intraindividuo (Parks, 1967). Resulta importante tener en cuenta que ni los modelos de efectos fijos ni aleatorios resultan apropiados en nuestro contexto. Los modelos de efectos fijos se basan exclusivamente en la variación temporal de cada unidad de sección cruzada, algo que está limitado en nuestras variables clave, a saber, disparidades regionales y, especialmente, descentralización fiscal (ver Apéndice 5). Por otra parte, utilizar un modelo de efectos aleatorios implicaría suponer que nuestra muestra es aleatoria y proviene de una gran población, algo que obviamente no es nuestro caso, ya que nuestras unidades de sección cruzada son departamentos o regiones de Uruguay (Hsiao, 2003). Finalmente, en todas nuestras estimaciones incluimos efectos temporales a los efectos de controlar por shocks comunes a todos los individuos de nuestra muestra.

Otra cuestión metodológica fundamental a considerar refiere a la presencia de problemas de causalidad inversa. Esta se puede originar de varias formas en nuestro modelo empírico, lo que puede sesgar el impacto estimado de nuestras variables explicativas claves. Primero, pudiera ser el caso que en contextos con mayores disparidades regionales existiera una mayor presión por la centralización basada en una visión hacia el fortalecimiento de la capacidad redistributiva del gobierno central, o alternativamente, que una mayor descentralización sea percibida como una contribución hacia la convergencia regional (Lessmann, 2012). Segundo, disparidades regionales significativas pudieran conducir a conflictos redistributivos sobre la distribución territorial de los recursos, lo que

13 Para detalles de la mecánica e interpretación de modelos de interacción ver, por ejemplo, Brambor et al. (2006). 
podría contrarrestar las políticas orientadas hacia una gobernanza más eficiente a nivel central o subnacional (Kyriacou y Roca, 2013). Para tratar con la causalidad reversa aplicamos dos aproximaciones. En primer lugar, consideramos una técnica de variables instrumentales basada en mínimos cuadrados generalizados realizables en dos etapas (FGLS-TS, por su denominación en inglés); utilizando los valores rezagados de nuestras variables endógenas (descentralización fiscal y calidad de gestión de gobierno) como instrumentos. Más específicamente, dado que estimaremos dos tipos de modelos: un primer modelo con datos anuales, y un segundo modelo con promedios trianuales como forma de controlar la influencia del ciclo económico; en ambos casos utilizamos los valores rezagados de estas supuestas variables endógenas como instrumentos. En segundo lugar, utilizamos estimadores generalizados de momentos sistémicos (SYS-GMM, por su denominación en inglés) sugeridos por Arellano y Bover (1995) y Blundell y Bond (1998). Estos estimadores resultan particularmente útiles en nuestro caso, debido a que preservan la información que proviene de la dimensión cross-section de nuestro panel. Esta información se perdería si empleáramos estimadores generalizados de momentos (GMM) en primeras diferencias (Arellano y Bond, 1991). Estos últimos explotan la variación de serie temporal de los datos, lo que no resulta apropiado cuando las variables son persistentes como es el caso de nuestras medidas de disparidades regionales y descentralización fiscal. De hecho, basados en simulaciones de Monte Carlo, Blundell y Bond (1998) han demostrado que el estimador SYS-GMM se comporta de mejor forma que el estimador en primeras diferencias cuando las variables son persistentes. Al sumar la ecuación original en niveles (con las primeras diferencias rezagadas como instrumentos) a un sistema de ecuaciones que también incluye las ecuaciones en primeras diferencias (con los niveles rezagados como instrumentos), el estimador SYS-GMM utiliza la dimensión de sección cruzada de los datos y tiene la ventaja añadida de controlar por efectos específicos de individuo ${ }^{14}$.

Finalmente, debido a que al construir nuestro indicador de calidad de gestión de gobierno como la suma simple de tres dimensiones, hipotéticamente, podrían existir dos gobiernos departamentales totalmente diferentes que podrían obtener la misma calificación, se optó por realizar un último análisis de robustez de los modelos estimados. De hecho, se procedió a estimar los diferentes modelos empíricos considerando por separado cada una de las tres dimensiones del indicador de calidad de gestión de gobierno.

\section{Resultados}

En la Tabla 1 presentamos los principales resultados de nuestras regresiones. Las primeras tres columnas presentan las estimaciones basadas en datos anuales; mientras que las últimas tres columnas emplean promedios trianuales en un esfuerzo por reducir las fluctuaciones cíclicas de corto plazo y, por tanto, la influencia del ciclo económico. De hecho, esto último nos permite concen-

14 Para aplicación de estimadores SYS-GMM en contextos similares, ver Voitchovsky (2005) y Castelló-Climent (2010). 


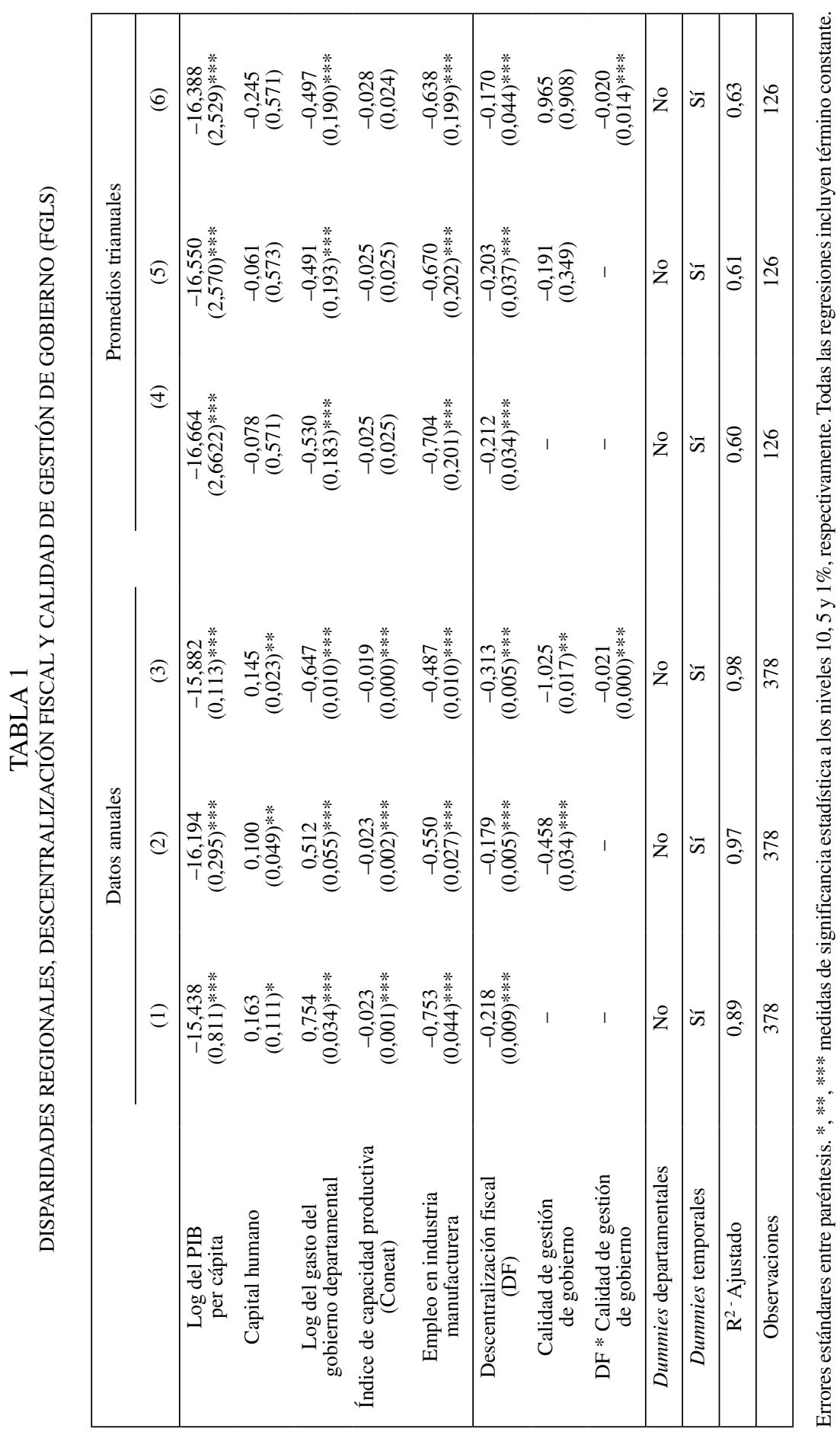


trarnos en relaciones de tipo estructural (ver también, Lessmann, 2009 y 2012; Rodríguez Pose y Ezcurra, 2010; Kyriacou et al., 2014).

El impacto de nuestras variables de control sobre las disparidades regionales se encuentra en línea con los trabajos empíricos previos. Un mayor nivel de PIB per cápita departamental reduce las disparidades regionales. A saber, las regiones (departamentos) más ricas tienden a exhibir menores disparidades con relación a la región más rica (Lessman, 2012; Kyriacou y Roca, 2013; Kyriacou et al., 2014). También encontramos que el gasto total del gobierno departamental, gasto que no es autónomo, aumenta las disparidades regionales. A su vez, no encontramos un efecto significativo del capital humano, es decir, de los diferenciales en años de educación de la población sobre las disparidades regionales, aunque este resultado deber ser considerado con cierta precaución, debido al hecho de que este indicador es solo una aproximación al stock de capital humano (Barro and Lee, 2001). Por su parte, el indicador de estructura industrial del empleo es significativo y negativo, por lo que estructuras productivas con mayor empleo industrial tenderían a disminuir las divergencias de ingresos regionales. Por detrás de este resultado está el hecho de que los departamentos que reportan menores ingresos laborales se asocian a las estructuras departamentales basadas en el sector primario y en servicios que en general se relacionan con el comercio local de proximidad, ya que el turismo es un sector significativo para el perfil productivo solo en el departamento de Maldonado. Finalmente, se observa que nuestro indicador de productividad de los suelos departamentales disminuye las disparidades regionales.

$\mathrm{Al}$ analizar el impacto de nuestras variables claves, descentralización fiscal, calidad de gestión de gobierno, y su efecto conjunto, emergen resultados interesantes. La descentralización fiscal tiende a reducir las disparidades regionales. Este efecto es significativo tanto con datos anuales (columna 1) como con promedios trianuales (columna 4). Cuando introducimos la calidad de gestión de gobierno en nuestro modelo empírico (columnas 2 y 5) encontramos que esta variable tiene un efecto significativo y negativo sobre las disparidades regionales, manteniendo la significancia y signo de la variable de descentralización fiscal. A su vez, el rol de la calidad de gestión se vuelve claro cuando se interacciona con la descentralización fiscal (columnas 3 y 6). Recordemos que supusimos que es probable que los problemas de gobernanza relacionados con la descentralización fiscal sean mayores en regiones con indicadores más pobres de calidad de gestión de gobierno, pudiendo opacar las ganancias esperadas en términos de eficiencia de la descentralización fiscal con relación a la convergencia regional. Esta expectativa se ve respaldada por el hecho de que el término de interacción con la descentralización fiscal es siempre negativo y estadísticamente significativo en nuestras regresiones.

La Tabla 2 presenta los resultados de regresión al considerar los problemas de causalidad inversa. Las primeras tres columnas consideran datos anuales y aplican FGLS-TS utilizando un rezago anual de los valores de la descentralización fiscal y la calidad de gestión de gobierno como instrumentos. De la misma forma, las columnas 4, 5 y 6 estiman el modelo con promedios trianuales, considerando como instrumentos los valores rezagados de estas variables. A su vez, las columnas 7, 8 y 9 consideran datos anuales y aplican SYS-GMM, utilizando un rezago anual de los valores de la descentralización fiscal y la calidad de gestión de gobierno como instrumentos. Finalmente, las columnas 10, 11 y 12 


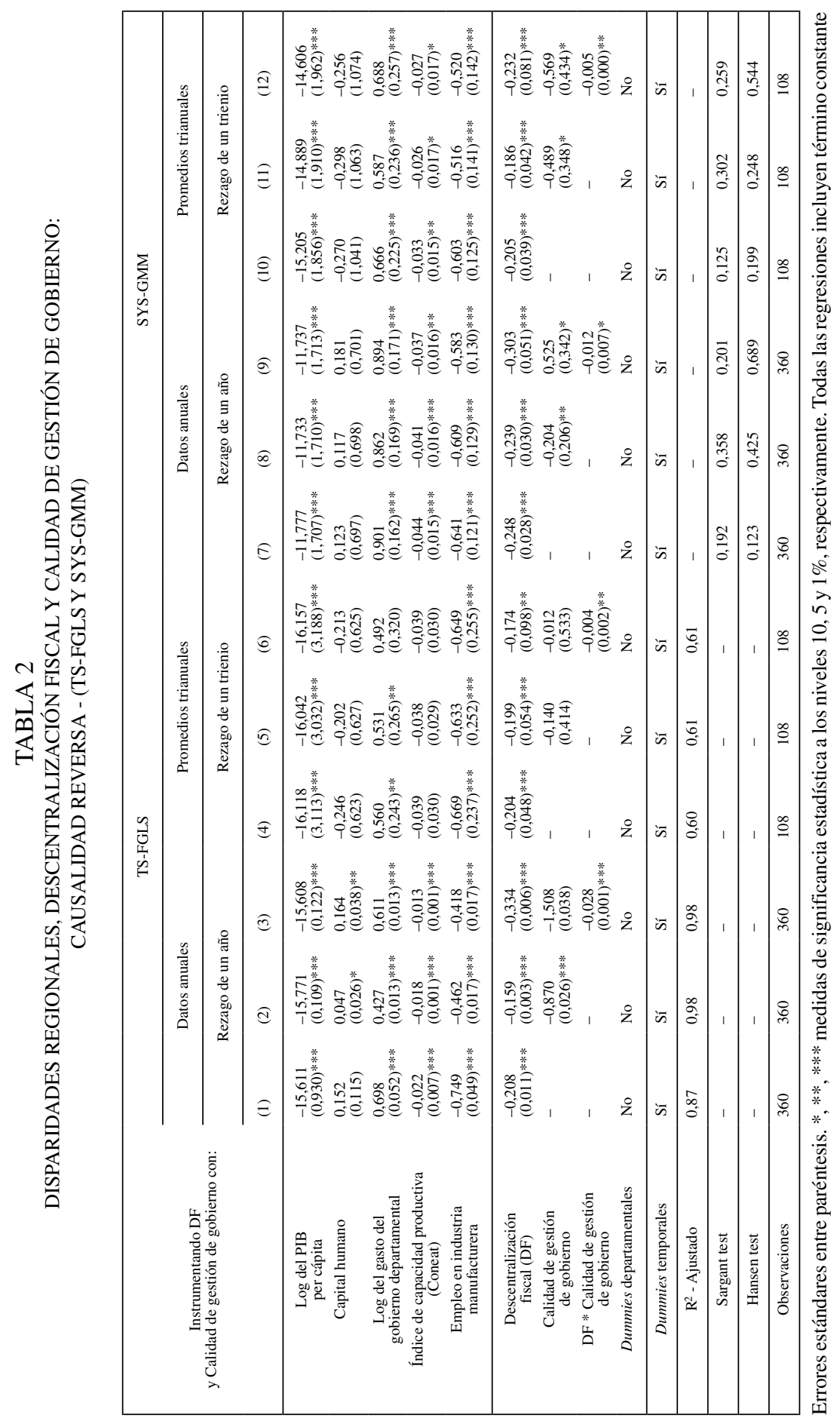


estiman el modelo con promedios trianuales, considerando como instrumentos los valores rezagados de estas variables. Los resultados obtenidos confirman los resultados exhibidos en la Tabla 1. En general nuestros resultados muestran que la descentralización fiscal reduce por sí sola las disparidades regionales en Uruguay, y que este efecto se ve potenciado ante la presencia de una mayor calidad de gestión del gobierno regional o departamental.

Por último, es importante señalar que se realizó un análisis de robustez de los modelos estimados, considerando por separado cada una de las tres dimensiones del indicador de calidad de gestión de gobierno (véase apéndice 6). Con relación a este ejercicio, debemos señalar que los principales resultados obtenidos se mantienen para cada una de las dimensiones consideradas. De todas formas, resulta importante observar que el impacto del indicador compuesto, que considera la suma de las tres dimensiones, permite obtener un impacto más robusto en términos de significancia y valor. De hecho, las diferentes varianzas explicadas en los modelos que consideran el indicador compuesto resultan mayores que en el caso de los modelos con la desagregación de las dimensiones (véase Tabla 1).

\section{Conclusiones}

En este artículo examinamos cómo la calidad de gestión de gobierno influencia el efecto de la descentralización fiscal sobre las disparidades regionales. Si bien existe la expectativa de que la descentralización fiscal pueda contribuir a una reducción en las disparidades regionales, debido a que estimula a que los gobiernos subnacionales estén mejor informados y fomenta la competencia interjurisdiccional, existe también el problema de que esta convergencia no se vea materializada debido a problemas de gestión de gobierno en estos menores niveles de administración.

Considerando este marco de análisis, en este artículo exploramos como media la calidad de gestión de gobierno en la relación entre descentralización fiscal y disparidades regionales, en una muestra de departamentos de Uruguay durante el período 1990-2010. Específicamente, explotamos la intuición de que los problemas de gobernanza relacionados con la descentralización pueden verse agravados en regiones con una calidad de gestión de gobierno más baja. Considerando esto, incluimos una medida de calidad de gestión de gobierno en las regresiones de disparidades regionales, y un término de interacción de esta medida con la descentralización fiscal para considerar el efecto mediador de la calidad de gestión.

Se encuentra que, controlando por la interacción entre descentralización fiscal y calidad de gestión de gobierno, el impacto de la descentralización fiscal es mayor que cuando esta se considera en forma aislada.

Desde una perspectiva de política, nuestros resultados tienen claras implicaciones. En primer lugar, el trabajo muestra evidencia de que por sí misma la descentralización, entendida como un mayor margen de autonomía fiscal que permita una mayor porción de los ingresos presupuestales con origen propio, favorece la convergencia regional. Por lo tanto, además de analizar y revisar el esquema de transferencias actualmente vigente en Uruguay, parecería adecuado pensar en las posibilidades que ofrece la reformada Constitución de 1996 para aumentar las fuentes propias de recursos de los gobiernos departamentales. 
En segundo lugar, si bien resultaría importante avanzar en la descentralización de recursos, es necesario también considerar ciertas precauciones. Las regiones que se encuentran "equipadas" con instituciones de buena calidad serán más capaces de aprovechar los beneficios potenciales de la descentralización fiscal en beneficio de su desarrollo. Sin embargo, si existen regiones con claros problemas de gestión, otorgarles a estos gobiernos subnacionales una mayor autonomía podría ampliar las diferencias de ingresos con el resto de las regiones, conduciendo a una mayor divergencia regional. Al respecto, la construcción de capacidades en los gobiernos subnacionales debería ser también parte del rol descentralizador de un proceso impulsado por el Gobierno Central, de forma de generar un avance escalonado, donde mayores capacidades habiliten mayores márgenes de autonomía. Más específicamente, se debería considerar que la creación de capacidades a nivel subnacional es un aspecto fundamental para el éxito del incremento de la calidad de gestión, por lo que todo proceso de descentralización fiscal debe estar acompañado de políticas de fortalecimiento institucional.

En tercer lugar, se considera que una mayor calidad de gestión de gobierno se alcanzará siempre y cuando una mayor descentralización fiscal implique que las transferencias de fuentes de generación de recursos propios sea exitosa, es decir, cuando el nivel subnacional sea capaz de recaudar recursos igual o mejor que cuando estos estaban a cargo del Gobierno Central, y no sean producto de transferencias que dependen de la "coparticipación tributaria nacional", que si bien pueden estar reduciendo la disparidad regional no necesariamente están incrementando la calidad de gestión.

\section{Bibliografía}

Acemoglu, D.; Johnson, S.; Robinson, J. (2005). Institutions as the fundamental cause of long-run growth. In: Aghion, P.; Durlauf, S. (eds.), Handbook of economic growth. Elsevier, Amsterdam, North Holland (pp. 385-472).

Akai, N.; Hosio, M. (2009). Fiscal decentralization, commitment and regional inequality: evidence for state-level, cross-sectional data for the United States. Journal of Income Distribution 18 (1): 113-129.

Arocena, J. (2008). Los desafíos de la descentralización y la participación ciudadana en el Uruguay, en Cuadernos para el Desarrollo Local. Diálogos por la Descentralización, Año 1, № 1, pp. 17-34, PNUD, Programa ART Uruguay.

Bardhan, P. (2002). Decentralization of governance and development. Journal of Economic Perspectives 16 (4): 185-205.

Bardhan, P.; Mookherjee, D. (2000). Capture and governance at local and national levels. American Economic Review 90 (2): 135-139.

Barro, R. and Lee, J. (2001). "International Data on Educational Attainment: Updates and Implications". Oxford Economic Papers, Oxford University Press, vol. 53 (3), pp. 541-563, July.

Bonet, J. (2006). Fiscal decentralization and regional income disparities: Evidence from the Colombian experience. Annals of Regional Science 40: 661-67.

Brambor, T.; Clark, W.; Golder, M. (2006). Understanding interaction models: improving empirical analyses. Political Analysis 14: 63-82. 
Brennan, G.; Buchanan, J. (1980). The power to tax. Analytical foundations of a fiscal constitution. Cambridge University Press, Cambridge.

Breton, A. (1996). Competitive governments. An economic theory of politics and public finance. Cambridge University Press, New York.

Cai, H.; Treisman, D. (2005). Does competition for capital discipline government? Decentralization, globalization and public policy. American Economic Review 95 (3): 817-830.

Calamai, L. (2009). The link between devolution and regional disparities: evidence from Italian regions. Environment and Planning A 41: 1129-1151.

Cardozo, M. y Ziccardi, A. (2010). Descentralización y participación ciudadana. Un análisis de las políticas sociales. Informe Final. Agenda Nacional de Descentralización, Uruguay Integra, OPP.

Castelló-Climent, A. (2010). Inequality and growth in advanced economies: an empirical investigation. Journal of Economic Inequality 8: 293-321.

CEDES (2010). Diseño institucional y descentralización territorial en un país unitario y centralizado como Uruguay. Informe Final. Agenda Nacional de Descentralización, Uruguay Integra, OPP.

Ezcurra, R.; Pascual, P. (2008). Fiscal decentralization and regional disparities: Evidence from several European Union countries. Environment and Planning A 40: 1185-1201.

Hsiao, C. (2003). Analysis of panel data. Cambridge University Press.

Jin, H.; Yingyi, Q.; Weingast, B. (2005). Regional decentralization and fiscal incentives: Federalism Chinese style. Journal of Public Economics 89 (9-10): 1719-1742.

Keen, M.; Marchand, M. (1997). Fiscal competition and the pattern of public spending. Journal of Public Economics 66: 33-53.

Kanbur, R.; Zhang, X. (2005). Fifty years of regional inequality in China: a journey through revolution, reform and openness. Review of Development Economics 9 (1): 87-106.

Kyriacou, A. (2012). Ethnic segregation and the quality of government: the importance of regional diversity. Constitutional Political Economy 23 (2): 166-180.

Kyriacou, A.; Roca-Sagalés, O. (2009). Fiscal decentralization and the quality of government: Evidence from panel data. Hacienda Pública Española 189 (2): 131-156.

Kyriacou, A.; Roca-Sagalés, O. (2011a). Fiscal and political decentralization and government quality. Environment and Planning C (Government and Policy), 29 (2): 204-223.

Kyriacou, A.; Roca-Sagalés, O. (2011b). Fiscal decentralization and government quality in the OECD. Economics Letters 111 (3): 191-193.

Kyriacou, A.; Roca-Sagalés, O. (2012). The impact of EU structural funds on regional disparities within member states. Environment and Planning $\mathrm{C}$ (Government and Policy) 30 (2): 267-281.

Kyriacou, A.; Roca-Sagalés, O. (2013). Regional disparities and government quality: Redistributive conflict crowds out good government. Forthcoming, Spatial Economic Analysis.

Kyriacou, A. P.; Muinelo-Gallo, L. and Roca-Sagalés, O. (2014). "Fiscal decentralization and regional disparities: The importance of good governance". Papers in Regional Science. Forthcoming. 
Lessmann, C. (2009). Fiscal decentralization and regional disparity: Evidence from cross section and panel data. Environment and Planning A 41: 2455-73.

Lessmann, C. (2012). Regional inequality and decentralization: an empirical analysis. Environment and Plannning A 44: 1363-1388.

Lin, S.; Kim, D.; Huang, H.; Yeh, C. (2009). Nonlinearity between inequality and growth, Studies in Nonlinear Dynamics Econometrics 13 (2): Article 3.

Martínez-Vázquez, J.; MacNab, R. M. (2003). "Fiscal Decentralization and Economic Growth", World Development, Vol. 39 (9), pp. 1597-1661.

Oates, W. (1972). "Fiscal Federalism”, New York: Harcourt Brace Jovanovich.

Oates W (1993). Fiscal decentralization and economic development. National Tax Journal 46 (2): 237-243.

Oates, W. (1999). An essay on fiscal federalism. Journal Economic Literature 37: $1120-49$.

Parks, R. (1967). Efficient estimation of a system of regression equations when disturbances are both serially and contemporaneously correlated. Journal of the American Statistical Association 62: 500-09.

Prud'homme, R. (1995). On the dangers of decentralization. World Bank Research Observer 10 (2): 201-20.

Qian, Y.; Roland, G. (1998). Federalism and the soft budget constraint. American Economic Review 88 (5): 1143-1162.

Qian, Y.; Weingast, B. (1997). Federalism as a commitment to preserving market incentives. Journal of Economic Perspectives 11: 83-92.

Qiao, B.; Martínez-Vázquez, J.; Xu, . (2008). The trade-off between growth and equity in decentralization policy: China's experience. Journal of Development Economics 86 (1): 112-128.

Rodríguez Miranda, A. (2014). Desarrollo económico y disparidades territoriales en Uruguay, EL FUTURO EN FOCO. Cuadernos sobre Desarrollo Humano $\mathrm{N}^{\mathrm{o}}$ 03, PNUD Uruguay.

Rodden, J.; Rose-Ackerman, S. (1997). Does federalism preserve markets? University of Virginia Law Review 83 (7): 1521-1572.

Rodríguez-Pose, A. (2010). Do institutions matter for regional development in the EU? Imdea Working Paper series in Economics and Social Sciences 2010/2, Madrid.

Rodríguez-Pose, A. (2012). Trade and regional inequality. Economic Geography 88 (2): 109-136.

Rodríguez-Pose, A.; Ezcurra, R. (2010). Does decentralization matter for regional disparities? A cross-country analysis. Journal of Economic Geography 10: 619-44.

Rodrik, D.; Subramanian, F.; Trebbi, F. (2004). Institutions rule: The primacy of institutions over geography and integration in economic development. Journal of Economic Growth 9: 131-65.

Salmon, P. (1987). Decentralization as an incentive scheme. Oxford Review of Economic Policy 3 (2): 24-43.

Silva, J. (2005). Devolution and regional disparities in the Philippines: is there a connection? Environment and Planning C (Government and Policy) 23: 399-417.

Tabellini, G. (2010). Culture and institutions: Economic development in the regions of Europe. Journal of the European Economic Association 8 (4): 677-716. 
Voitchovsky, S. (2005). Does the profile of income inequality matter for economic growth? Distinguishing between the effects of inequality in different parts of the income distribution. Journal of Economic Growth 10: 273-296.

Williamson, J. (1965). Regional inequality and the process of national development: A description of patterns. Economic Development and Cultural Change 13: $3-45$.

Wooldridge, J. (2010). Econometric Analysis of Cross Section and Panel Data. Second Edition. MIT Press.

Zhuravskaya, E. (2000). Incentives to provide local public goods: Fiscal federalism, Russian style. Journal of Public Economics 76 (3): 337-368. 


\section{APÉNDICE 1}

\section{División Política de la República Oriental} DEL URUGUAY

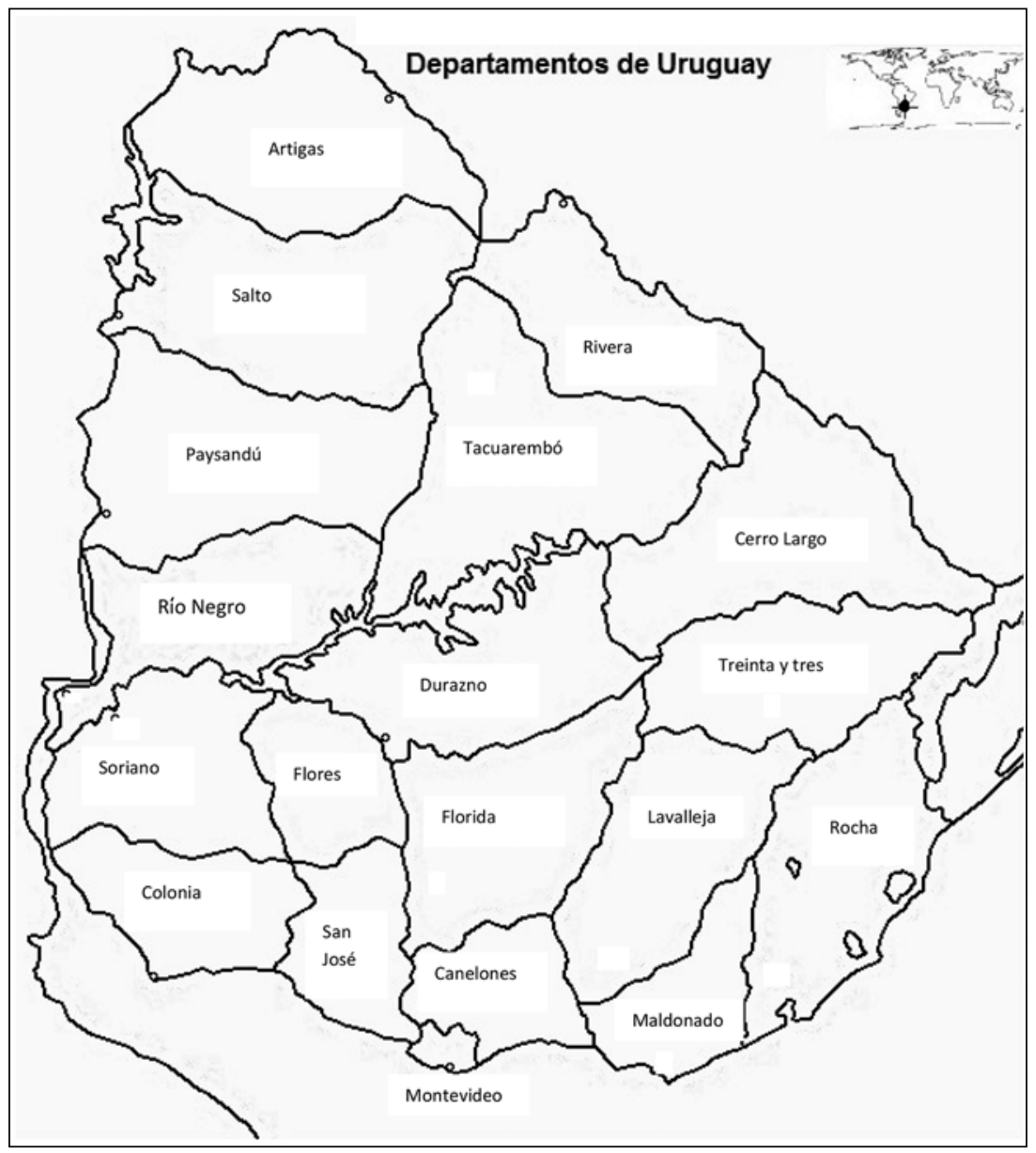

Fuente: Oficina Nacional de Servicio Civil de la Presidencia de la República, Uruguay. 


\section{APÉNDICE 2 \\ LISTA DE DEPARTAMENTOS \\ (REGIONES)}

Artigas, Canelones, Cerro Largo, Colonia, Durazno, Flores, Florida, Lavalleja, Maldonado, Paysandú, Salto, San José, Soriano, Río Negro, Rivera, Rocha, Tacuarembó, Treinta y Tres, Montevideo (valor de referencia).

NOMENCLATURA DE DEPARTAMENTOS

\begin{tabular}{|lc|}
\hline Departamento & Nomenclatura \\
\hline Artigas & ART \\
Canelones & CAN \\
Cerro Largo & CL \\
Colonia & COL \\
Durazno & DUR \\
Flores & FLO \\
Florida & FLOR \\
Lavalleja & LAV \\
Maldonado & MAL \\
Paysandú & PAY \\
Río Negro & RNEG \\
Rivera & RIV \\
Rocha & ROC \\
Salto & SAL \\
San José & SJ \\
Soriano & SOR \\
Tacuarembó & TAC \\
Treinta y tres & TyT \\
\hline
\end{tabular}

Fuente: Oficina Nacional de Servicio Civil de la Presidencia de la República, Uruguay. 


\section{APÉNDICE 3 \\ INDICADOR DE CALIDAD DE GESTIÓN DE GOBIERNO}

El indicador final resulta de la suma simple de tres dimensiones, que refieren a variables categóricas de valor 0, 1, 2 y 3. Estas dimensiones son resultado fiscal, remuneración promedio de los funcionarios y porcentaje de personal presupuestado en el total de funcionarios. Los umbrales de cada dimensión se escogieren a base de su distribución empírica. En la siguiente Tabla se explicitan estos umbrales para cada una de las tres dimensiones analizadas:

\begin{tabular}{|c|c|c|c|}
\hline $\begin{array}{c}\text { Valor } \\
\text { categoría }\end{array}$ & $\begin{array}{c}\text { Resultado } \\
\text { fiscal } \\
\text { (en \% del PIB } \\
\text { departamental) }\end{array}$ & $\begin{array}{l}\text { Remuneración } \\
\text { promedio de los } \\
\text { funcionarios } \\
\text { (en pesos } \\
\text { constantes de } \\
1995)\end{array}$ & $\begin{array}{l}\text { Porcentaje de } \\
\text { funcionarios } \\
\text { presupuestados } \\
\text { en el total } \\
\text { de personal }\end{array}$ \\
\hline 0 & $\begin{array}{c}\text { Menor que } \\
-1 \%\end{array}$ & $\begin{array}{c}\text { Menor que } \\
20.000 \text { pesos }\end{array}$ & $\begin{array}{c}\text { Menor que } \\
25 \%\end{array}$ \\
\hline 1 & $\begin{array}{c}\text { Entre }-1 \% \text { y } \\
0 \%\end{array}$ & $\begin{array}{c}\text { Entre } 20.000 \mathrm{y} \\
45.000\end{array}$ & $\begin{array}{c}\text { Entre } 25 \% \text { y } \\
50 \%\end{array}$ \\
\hline 2 & $\begin{array}{c}\text { Entre } 0 \% \mathrm{y} \\
0,5 \%\end{array}$ & $\begin{array}{c}\text { Entre } 45.000 \mathrm{y} \\
65.000\end{array}$ & $\begin{array}{c}\text { Entre } 50 \% \text { y } \\
75 \%\end{array}$ \\
\hline 3 & $\begin{array}{c}\text { Mayor que } \\
0,5 \%\end{array}$ & $\begin{array}{c}\text { Mayor que } \\
65.000\end{array}$ & $\begin{array}{c}\text { Mayor que } \\
75 \%\end{array}$ \\
\hline
\end{tabular}

Fuentes: Oficina de Planeamiento y Presupuesto de la Presidencia de la República, Uruguay, y Oficina Nacional de Servicio Civil de la Presidencia de la República, Uruguay.

Considerando este marco de análisis, nuestro indicador de calidad de gestión de gobierno varía entre 0 (peor calidad de gobierno) y 9 (mayor calidad de gobierno). 


\section{APÉNDICE 4 \\ FUENTES DE DATOS}

\begin{tabular}{|c|c|c|}
\hline Variable & Definición & Fuente \\
\hline $\begin{array}{l}\text { Disparidades } \\
\text { regionales }\end{array}$ & $\begin{array}{l}\text { Coeficiente de variación } \\
\text { calculado con ingreso } \\
\text { promedio per cápita de los } \\
\text { hogares. }\end{array}$ & $\begin{array}{l}\text { Encuesta Continua de } \\
\text { Hogares - Instituto Nacional } \\
\text { de Estadística de Uruguay }\end{array}$ \\
\hline $\begin{array}{l}\text { Descentralización } \\
\text { fiscal }\end{array}$ & $\begin{array}{l}\text { Porcentaje que representan } \\
\text { los ingresos de origen } \\
\text { departamental en el total } \\
\text { de ingresos del Gobierno } \\
\text { General Nacional. }\end{array}$ & $\begin{array}{l}\text { Oficina de Planeamiento y } \\
\text { Presupuesto - Presidencia } \\
\text { de la República, Ministerio } \\
\text { de Economía y Finanzas, } \\
\text { Contaduría General de } \\
\text { la Nación y Banco de } \\
\text { Previsión Social. }\end{array}$ \\
\hline $\begin{array}{l}\text { Calidad de gestión } \\
\text { de gobierno }\end{array}$ & $\begin{array}{l}\text { Suma de tres dimensiones } \\
\text { que varían entre } 0 \text { y } \\
\text { 3: resultado fiscal, } \\
\text { porcentaje de funcionarios } \\
\text { presupuestados, } \\
\text { remuneración media. El } \\
\text { indicador final varía entre } \\
0 \text { y } 9 \text {. }\end{array}$ & $\begin{array}{l}\text { Resultado fiscal (ingresos } \\
\text { menos egresos totales) } \\
\text { y total de gasto en } \\
\text { remuneraciones del GD: } \\
\text { Oficina de Planeamiento y } \\
\text { Presupuesto - Presidencia } \\
\text { de la República. } \\
\text { Porcentaje de funcionarios } \\
\text { presupuestados y cantidad } \\
\text { de funcionarios: Oficina } \\
\text { Nacional de Servicio Civil - } \\
\text { Presidencia de la República. }\end{array}$ \\
\hline $\begin{array}{l}\text { Log del PIB } \\
\text { per cápita }\end{array}$ & $\begin{array}{l}\text { Logaritmo del PIB per } \\
\text { cápita departamental. }\end{array}$ & $\begin{array}{l}\text { Oficina de Planeamiento y } \\
\text { Presupuesto - Presidencia } \\
\text { de la República. }\end{array}$ \\
\hline $\begin{array}{l}\text { Log del gasto } \\
\text { del gobierno } \\
\text { departamental }\end{array}$ & $\begin{array}{l}\text { Logaritmo del total de } \\
\text { egresos del gobierno } \\
\text { departamental. }\end{array}$ & $\begin{array}{l}\text { Oficina de Planeamiento y } \\
\text { Presupuesto - Presidencia } \\
\text { de la República. }\end{array}$ \\
\hline $\begin{array}{l}\text { Índice de } \\
\text { capacidad } \\
\text { productiva de la } \\
\text { tierra } \\
\text { (CONEAT) }\end{array}$ & $\begin{array}{l}\text { Promedios departamentales } \\
\text { de índice CONEAT. }\end{array}$ & $\begin{array}{l}\text { Comisión Nacional de } \\
\text { Estudio Agronómico de } \\
\text { la Tierra (CONEAT), } \\
\text { Dirección General de } \\
\text { Recursos Renovables del } \\
\text { Ministerio de Ganadería, } \\
\text { Agricultura y Pesca de } \\
\text { Uruguay. }\end{array}$ \\
\hline $\begin{array}{l}\text { Empleo en } \\
\text { industria } \\
\text { manufacturera }\end{array}$ & $\begin{array}{l}\text { Promedios departamentales } \\
\text { en } \% \text { del empleo total. }\end{array}$ & $\begin{array}{l}\text { Encuesta Continua de } \\
\text { Hogares - Instituto Nacional } \\
\text { de Estadística de Uruguay. }\end{array}$ \\
\hline $\begin{array}{l}\text { Capital } \\
\text { humano }\end{array}$ & $\begin{array}{l}\text { Años promedio de } \\
\text { educación formal de la } \\
\text { PEA. }\end{array}$ & $\begin{array}{l}\text { Encuesta Continua de } \\
\text { Hogares - Instituto Nacional } \\
\text { de Estadística de Uruguay. }\end{array}$ \\
\hline
\end{tabular}




\section{APÉNDICE 5 \\ ESTADÍSTICA DESCRIPTIVA}

\begin{tabular}{|c|c|c|c|c|c|c|}
\hline & & Media & $\begin{array}{l}\text { Desv. } \\
\text { estándar }\end{array}$ & Mínimo & Máximo & Observaciones \\
\hline $\begin{array}{l}\text { Disparidades } \\
\text { regionales }\end{array}$ & $\begin{array}{l}\text { Overall } \\
\text { Between } \\
\text { Within }\end{array}$ & 42,0836 & $\begin{array}{l}8,8980 \\
6,8731 \\
5,8686\end{array}$ & $\begin{array}{r}4,4070 \\
28,8672 \\
12,4003\end{array}$ & $\begin{array}{l}63,5422 \\
55,1539 \\
58,2173\end{array}$ & $\begin{array}{r}\mathrm{N}=378 \\
\mathrm{n}=18 \\
\mathrm{~T}=21\end{array}$ \\
\hline $\begin{array}{l}\text { Descentralización } \\
\text { fiscal }\end{array}$ & $\begin{array}{l}\text { Overall } \\
\text { Between } \\
\text { Within }\end{array}$ & 0,2543 & $\begin{array}{l}0,3159 \\
0,3121 \\
0,0738\end{array}$ & $\begin{array}{l}0,0419 \\
0,0765 \\
0,0233\end{array}$ & $\begin{array}{l}0,6582 \\
0,2889 \\
0,6178\end{array}$ & $\begin{array}{r}\mathrm{N}=378 \\
\mathrm{n}=18 \\
\mathrm{~T}=21\end{array}$ \\
\hline $\begin{array}{l}\text { Calidad de } \\
\text { gestión de } \\
\text { gobierno }\end{array}$ & $\begin{array}{l}\text { Overall } \\
\text { Between } \\
\text { Within }\end{array}$ & 3,568182 & $\begin{array}{r}1,791088 \\
1,074436 \\
1,45429\end{array}$ & $\begin{array}{r}0 \\
2,045455 \\
0,3333\end{array}$ & $\begin{array}{r}9 \\
5,681818 \\
6,886364\end{array}$ & $\begin{array}{r}\mathrm{N}=378 \\
\mathrm{n}=18 \\
\mathrm{~T}=21\end{array}$ \\
\hline $\begin{array}{l}\text { Log del PIB } \\
\text { per cápita } \\
\text { (departamental) }\end{array}$ & $\begin{array}{l}\text { Overall } \\
\text { Between } \\
\text { Within }\end{array}$ & 10,2363 & $\begin{array}{l}0,2699 \\
0,2031 \\
0,1451\end{array}$ & $\begin{array}{l}9,5864 \\
9,7768 \\
9,9115\end{array}$ & $\begin{array}{l}11,0080 \\
10,5484 \\
10,7433\end{array}$ & $\begin{array}{r}\mathrm{N}=378 \\
\mathrm{n}=18 \\
\mathrm{~T}=21\end{array}$ \\
\hline $\begin{array}{l}\text { Capital } \\
\text { humano }\end{array}$ & $\begin{array}{l}\text { Overall } \\
\text { Between } \\
\text { Within }\end{array}$ & 8,2200 & $\begin{array}{l}0,5101 \\
0,2547 \\
0,4458\end{array}$ & $\begin{array}{l}6,9694 \\
7,7898 \\
7,1020\end{array}$ & $\begin{array}{l}9,7487 \\
8,6061 \\
9,6624\end{array}$ & $\begin{array}{r}\mathrm{N}=378 \\
\mathrm{n}=18 \\
\mathrm{~T}=21\end{array}$ \\
\hline $\begin{array}{l}\text { Log del gasto } \\
\text { del gobierno } \\
\text { (departamental) }\end{array}$ & $\begin{array}{l}\text { Overall } \\
\text { Between } \\
\text { Within }\end{array}$ & 18,4774 & $\begin{array}{l}0,8392 \\
0,5374 \\
0,6563\end{array}$ & $\begin{array}{l}15,3668 \\
17,6924 \\
15,8251\end{array}$ & $\begin{array}{l}20,4419 \\
19,8799 \\
19,3731\end{array}$ & $\begin{array}{r}\mathrm{N}=378 \\
\mathrm{n}=18 \\
\mathrm{~T}=21\end{array}$ \\
\hline $\begin{array}{c}\text { Índice de capacidad } \\
\text { productiva de los suelos } \\
\text { (Coneat) }\end{array}$ & $\begin{array}{l}\text { Overall } \\
\text { Between } \\
\text { Within }\end{array}$ & 100,3889 & $\begin{array}{r}22,8536 \\
23,4850 \\
0\end{array}$ & $\begin{array}{r}68 \\
68 \\
10,3889\end{array}$ & $\begin{array}{r}137 \\
137 \\
100,3889\end{array}$ & $\begin{array}{r}\mathrm{N}=378 \\
\mathrm{n}=18 \\
\mathrm{~T}=21\end{array}$ \\
\hline $\begin{array}{l}\text { Empleo en } \\
\text { industria } \\
\text { manufacturera }\end{array}$ & $\begin{array}{l}\text { Overall } \\
\text { Between } \\
\text { Within }\end{array}$ & 11,40219 & $\begin{array}{r}11,40219 \\
2,964682 \\
0\end{array}$ & $\begin{array}{l}6,485992 \\
6,485992 \\
11,40219\end{array}$ & $\begin{array}{l}17,94415 \\
17,94415 \\
11,40219\end{array}$ & $\begin{array}{r}\mathrm{N}=378 \\
\mathrm{n}=18 \\
\mathrm{~T}=21\end{array}$ \\
\hline
\end{tabular}




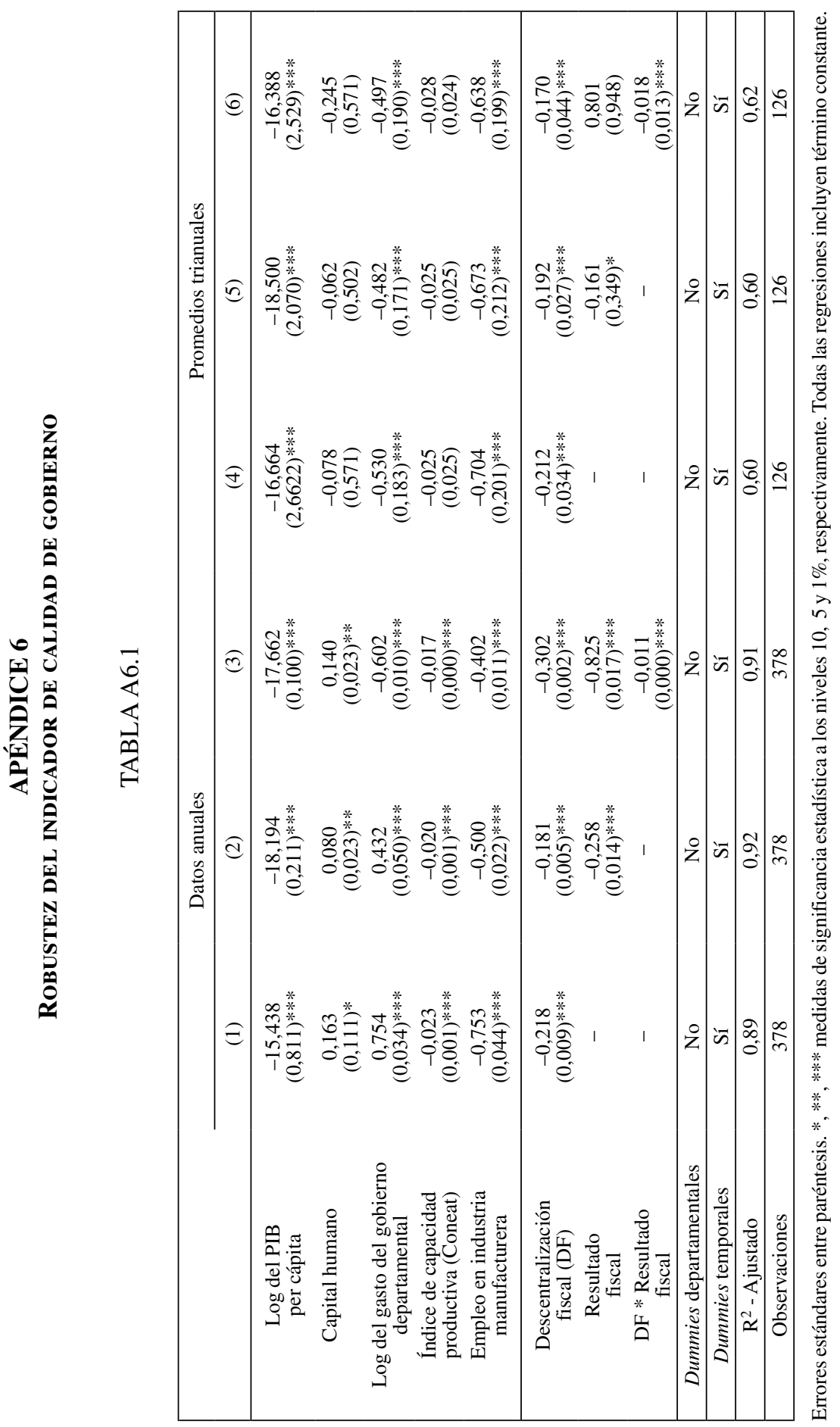




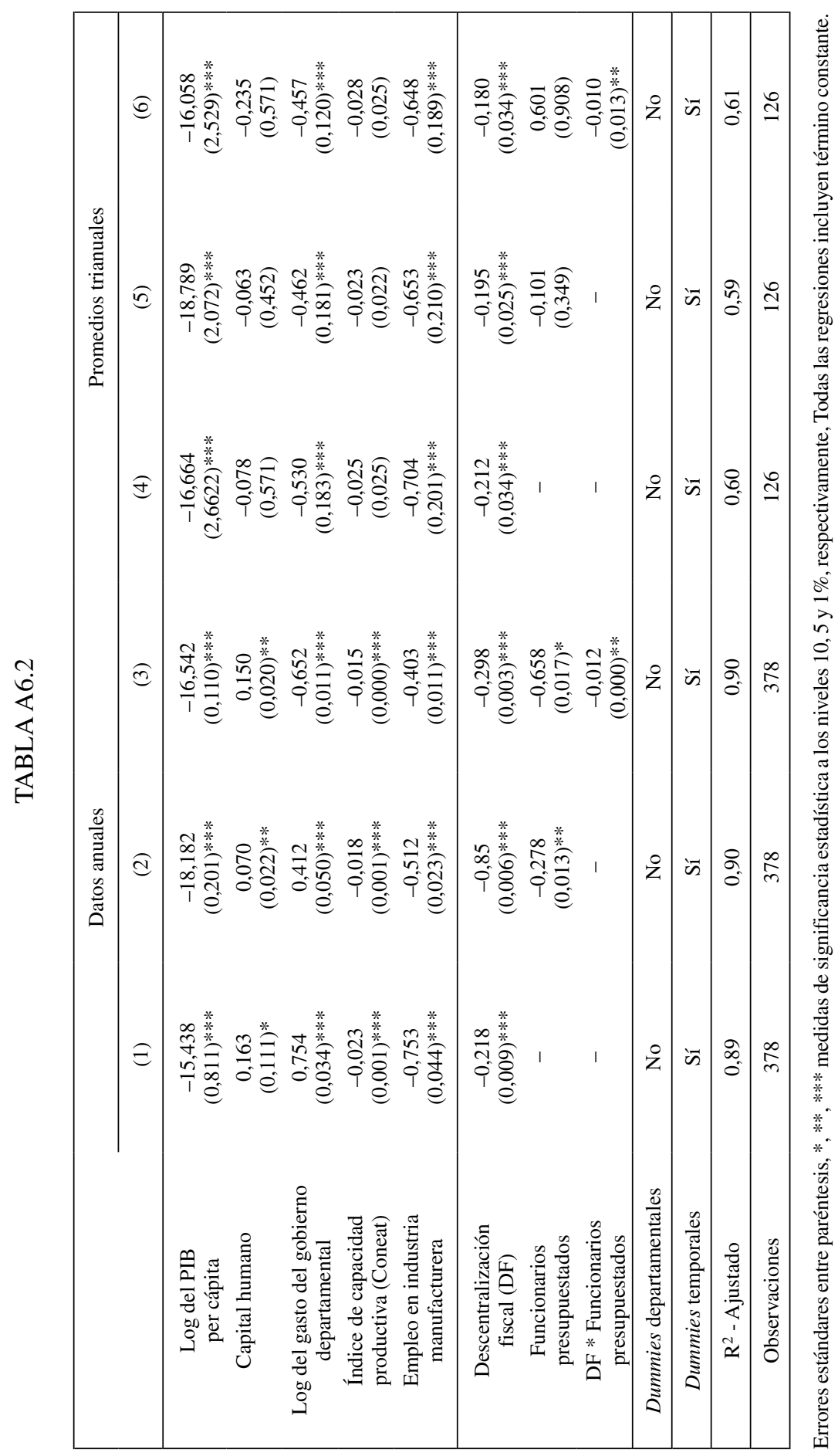




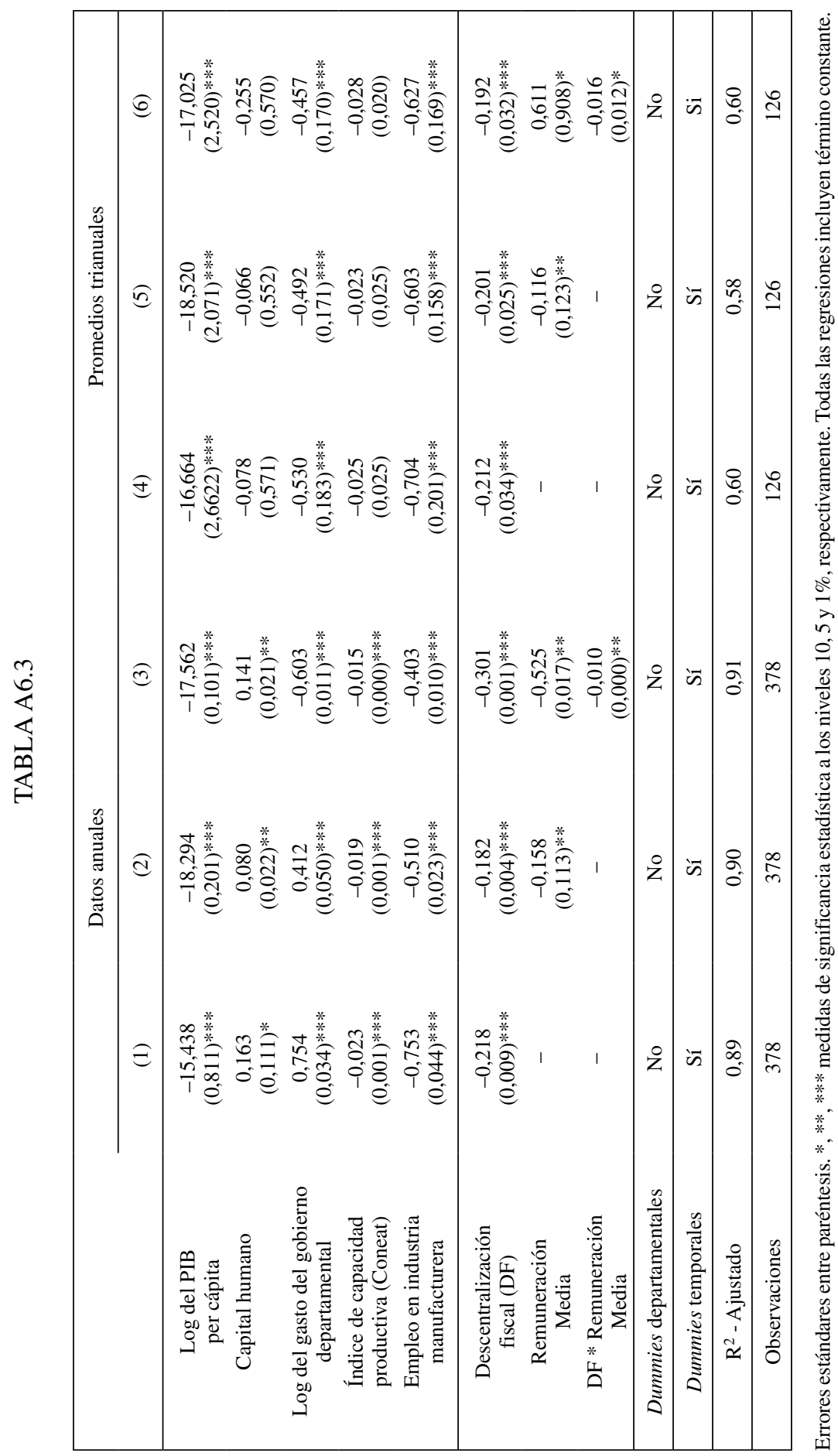

